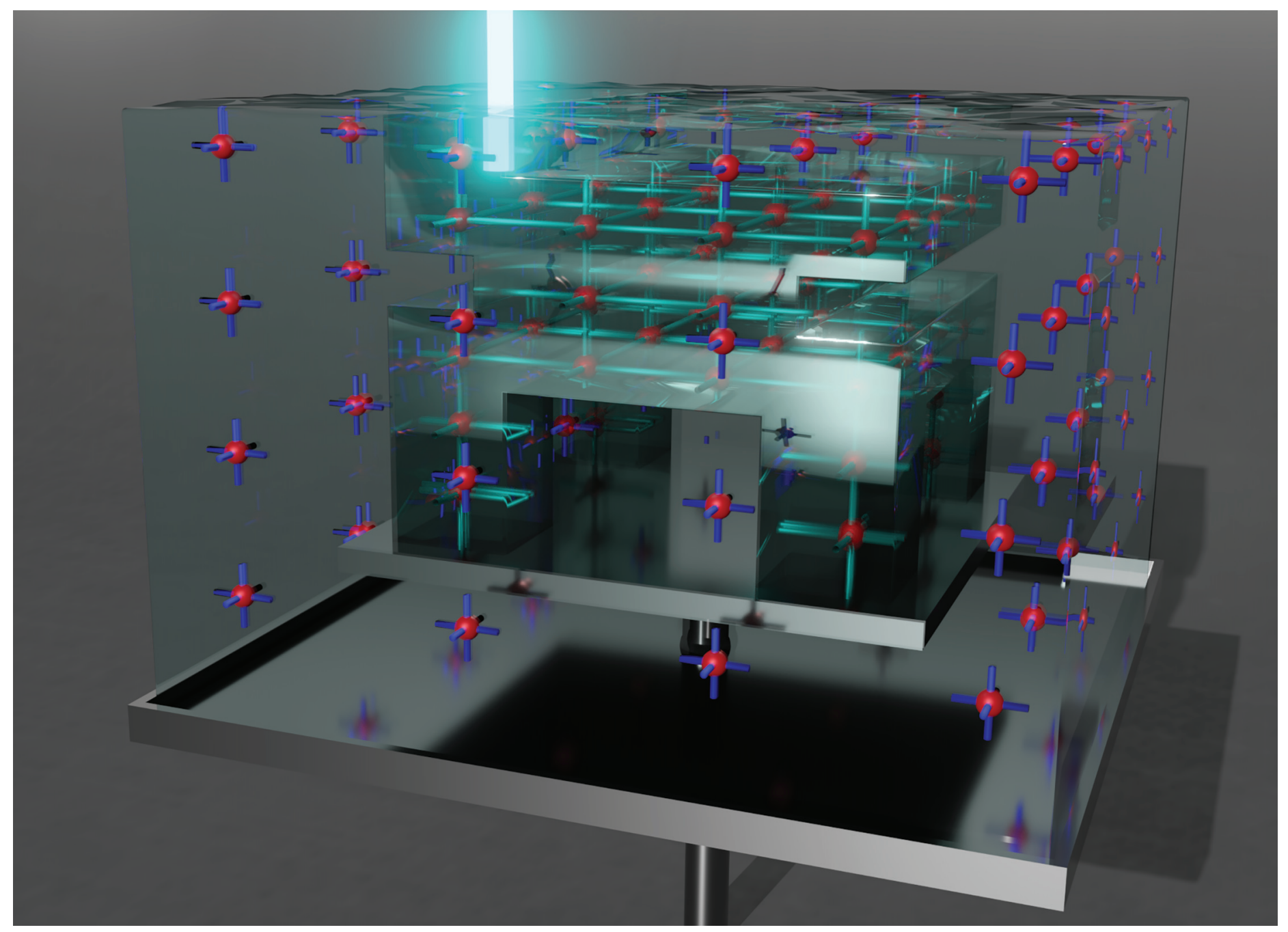

Highlighting a perspective article from Karlsruhe Institute of Technology and University of Heidelberg in Germany.

Hierarchical ordering in light-triggered additive manufacturing

Prof. Dr. Eva Blasco and Mr. Joel Monti present recent achievements in the development of polymeric materials with structural hierarchy for additive manufacturing using light, and their applications. This work highlights the opportunities provided by hierarchical ordering and additive manufacturing technologies for the development of advanced functional polymeric materials, and their implementation in the fabrication of smart devices.

\section{As featured in:}

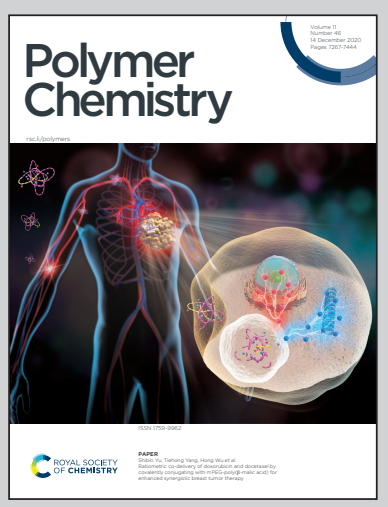

See Joël Monti and Eva Blasco, Polym. Chem., 2020, 11, 7316. 


\section{A) Check for updates}

Cite this: Polym. Chem., 2020, 11 7316

Received 28th July 2020, Accepted 7th October 2020

DOI: $10.1039 /$ d0py01077d rsc.li/polymers

\title{
Hierarchical ordering in light-triggered additive manufacturing
}

\author{
Joël Monti ${ }^{a}$ and Eva Blasco (iD) *a,b,c
}

\begin{abstract}
Additive manufacturing (AM) emerged, in the last decades, as a promising manufacturing technique for the low-cost fabrication of personalised 3D objects. Recently, this technology has been increasingly utilised, both in everyday life and in industry. Among the numerous AM techniques available, light-triggered AM allows for great shape resolution and a smooth surface, while being a relatively fast process. The increasing interest given to AM naturally motivated the development of novel 3D printable materials in order to keep on widening the possibilities of the techniques. Herein, we present an overview of the materials having been recently reported in the field, for which the incorporation of hierarchical ordering was essential to access novel functionalities and properties. In particular, hybrid materials such as fibreand nanocrystal-reinforced polymeric networks, liquid crystalline materials and metal-organic framework embedded printable materials along with their future prospects will be discussed.
\end{abstract}

\section{Introduction}

3D printing, or more generally additive manufacturing (AM), has gained, in the last years, an exponentially increasing popularity in everyday life. ${ }^{1}$ Indeed, this bottom-up, computeraided approach of fabrication is one of the choices for the fast and cost-effective prototyping of custom pieces. Moreover, structures with complex geometries are, in specific cases, only accessible by AM. Hence, not only can AM provide a powerful prototyping platform for development and design, but also it opens new opportunities for the fabrication of novel 3D structures. The current use of AM across disparate disciplines including aerospace, ${ }^{2,3}$ automotive, ${ }^{4,5}$ and food industries, ${ }^{6}$ medicine, ${ }^{7}$ and others ${ }^{8}$ is a clear proof of the vast impact of these technologies in modern fabrication processes.

Among all the materials utilised in AM, soft materials, and especially polymer-based inks, are part of the most promising printable materials due their excellent versatility and adaptability. ${ }^{9}$ Common AM techniques for polymeric materials include powder bed fusion, material and binder jetting, fused deposition modelling, direct ink writing and vat photopolymerisation. In recent years, various comprehensive reviews highlighting the state of the art in the field have been published. ${ }^{10}$ When focussing on truly and defined three dimen-

${ }^{a}$ Institute of Nanotechnology, Karlsruhe Institute of Technology (KIT), Hermann-vonHelmoltz-Platz 1, 76128 Karlsruhe, Germany.E-mail: eva.blasco@kit.edu

${ }^{b}$ Organisch-Chemisches Institut, University of Heidelberg, Im Neuenheimer Feld 270, 69120 Heidelberg

${ }^{c}$ Centre for Advanced Materials, University of Heidelberg, Im Neuenheimer Feld 225, 69120 Heidelberg. E-mail: eva.blasco@oci.uni-heidelberg.de sional AM, stereolithography (SLA), digital light processing (DLP), and more recently, continuous liquid interface production (CLIP) as well as 3D laser lithography based on multiphoton polymerisation are examples of technologies directly based on photochemical processes.

First patented by Hull et al. in $1986,{ }^{11}$ stereolithography (SLA) is known to be the original 3D-printing technology. ${ }^{12,13}$ Together with DLP, SLA is part of the more general class of "vat photopolymerisation processes". These techniques produce, layer by layer, 3D objects by the photopolymerisation of a photoresist disposed within a vat. The difference among them relies on the light source used. While SLA uses a low cross-section laser source which is scanned pixel by pixel throughout each layer using galvanometers for laser deviation, ${ }^{14,15}$ DLP uses a digital light projector screen as the light source, allowing the printing of an entire layer at once. ${ }^{16}$ As a result, DLP is a faster process than SLA. Both techniques allow the fabrication of pieces with high definition and surface smoothness, hence not requiring mechanical post-processing of the surface. ${ }^{17}$ Typically, resolutions between 25 and $100 \mu \mathrm{m}$ (depending on the technique and printer) can be achieved. ${ }^{9,18,19}$ Notwithstanding, they are facing several limitations: (i) the piece obtained straight after printing generally needs to be cured under UV-irradiation, in order to increase the crosslinking density, thus to enhance the material properties of the piece. ${ }^{20}$ (ii) Even after post-printing UV-curing, vat photopolymerisation processes generally produce brittle materials, with material properties that are not suitable for the construction of pieces purposed to endure strong mechanical stresses. $^{20-22}$ (iii) Supporting structures have to be printed together with the targetted structure to ensure a good anchor- 
ing to the stage of the printing device. ${ }^{23}$ Those have to be mechanically removed to isolate the final piece; anchor points are then likely to still be visible at the end of the process. Considering these features, conventional vat photopolymerisation processes are particularly well-adapted to applications in which high shape-definition prevails over mechanical strength, such as prototyping or the fabrication of moulds. ${ }^{24-27}$

More recently, continuous liquid interface production (CLIP) has emerged as a promising AM technique. This approach invented by DeSimone ${ }^{28,29}$ exploits the oxygen inhibition noticeably observed for the free-radical polymerisation of acrylates, to continuously leave the cross-linked part dipped in the fluid photoresist. ${ }^{30-32}$ Thanks to oxygen-inhibition, the deepest layer of the photoresist in the vat always consists of a non-crosslinked material, allowing the photopolymerisation to occur, in upper layers, at the interface of the cross-linked polymer and the oxygen-rich fluid photoresist. Moreover, due to the continuous printing, CLIP limits the impact on the material properties of the inter-layer junctions, creating pieces which behave consistently in all directions, contrary to conventional AM techniques. ${ }^{33}$

Moving to the micro- and nanoregime, 3D laser lithography based on two-photon polymerisation enables sub-micron resolution. In this technique, the use of femtosecond lasers is essential for making two-photon absorption processes sufficiently probable. During the last years, 3D laser printing is being established as a suitable approach for the fabrication of functional 3D micro- and nanostructures. ${ }^{34-39}$

Light-triggered AM relies on the formation of stable polymeric networks from a liquid monomer mixture using a light source. In particular, three photocrosslinking strategies are being commonly used: (i) free-radical polymerisation of vinyl monomers and cationic polymerisation of epoxides; (ii) thiolene(yne) free-radical polymerisation and (iii) photodimerisation reactions.

Methacrylate-containing monomers (in the presence of a photoinitiator $^{40-46}$ ) are, nowadays, the most broadly used inks in the context of light-triggered $\mathrm{AM}^{47}$ One of the main reasons is the wide variety of mono- and multi-functional meth(acrylates) that can be directly purchased. Furthermore, for customised synthetic photoresists, functional (meth)acrylate derivatives are particularly popular as they can be easily introduced within a chemical structure via addition under basic conditions using (meth)acryloyl chloride, ${ }^{48-51}$ or via esterification ${ }^{52,53}$ using acrylic acid.

Cationic ring-opening of multifunctional epoxide resins containing a photoacid generator as a trigger of the photocrosslinking is also employed in 3D printing. Epoxide monomers have some advantages over (meth)acrylates, noticeably regarding the oxygen insensitivity of the cationic photocrosslinking of epoxides, the lower shrinkage and greater strength of the final materials. ${ }^{54-56}$ However, the less straightforward synthesis of monomers and the reduced popularity are important shortcomings of epoxy resins when compared to (meth)acrylates. ${ }^{57}$

Thiol-ene(yne) photopolymerisation has been extensively exploited in the field, too. In addition to having the kinetic and thermodynamic features associated with the free-radical polymerisation mechanism, it also depicts specific advantages: ${ }^{58}$ thiol-ene(yne) shows a decent insensitivity to oxygen quenching, a noticeably less prominent polymerisation-caused shrinking than the free-radical polymerisation of acrylates ${ }^{59-61}$ and involves non-toxic chemicals. ${ }^{62}$ As a result, the thiol-ene coupling is popular for the $3 \mathrm{D}$ printing of elastomers and biocompatible elastomers or hydrogels; these materials are of great interest for tissue engineering, drug delivery technologies and in vivo processes. ${ }^{62-66}$ However, the final material usually exhibits a rather low crosslinking density. ${ }^{67}$ Besides, the elaboration, based on thiol-ene(yne) photopolymerisation, of materials with a higher cross-linking density has also been investigated. ${ }^{58-62,65,67-69}$

Photodimerisation reactions have also been successfully used either to fabricate films under UV-irradiation ${ }^{70-72}$ or for $3 \mathrm{D}$ printing. Unlike photopolymerisation reactions, the photoinduced dimerisation reaction does not require the presence of a photoinitiator since the reaction is self-initiated by the functional group. On the other hand, because dimerisation reactions do not proceed through a living propagation mechanism, photons are consumed in stoichiometric amounts. The $[2+2]$ photodimerisation of coumarins $\left(\lambda_{\max } \approx 340 \mathrm{~nm}\right)$ is one of the most prominent examples of such systems. ${ }^{73-76}$ Interestingly, the photo-induced dimerisation of amino acids containing a photooxidisable group, such as Trp, His, Tyr, Cys and Met, has also been used for 3D-printing. ${ }^{77-84}$

The photocrosslinking methods described above lead to the formation of 3D printed polymeric structures composed of, in most cases, an undefined internal structure due to the lack of control at the molecular level during the polymerisation processes. However, having a look at active natural materials (muscles, tendons, proteins, etc.), all of them exhibit ordering from the molecular to microscale. This structural hierarchy plays a crucial role in their performance in terms of mechanical properties and/or actuation. Therefore, the introduction of ordering in new functional printable materials is of outstanding interest in the field of AM.

Herein, we will discuss recent developments in the 3D printing of polymeric materials with structural hierarchy and their applications. By increasing the extent of ordering (anisotropy), selected recent examples of 3D printable hybrid materials and self-assembled materials, (i) liquid-crystalline materials and (ii) metal-organic frameworks (MOFs), will be presented, Fig. 1. In addition, future prospects and viewpoints for the incorporation of hierarchical order in materials for light-triggered AM will be discussed.

\section{Hybrid materials}

The final brittleness of the printed structures produced by light-triggered AM using conventional polymer-based inks is undeniably one of the main challenges that should be faced to allow a wider spreading of light-triggered AM technologies for the manufacturing of mechanically strong pieces. As discussed 


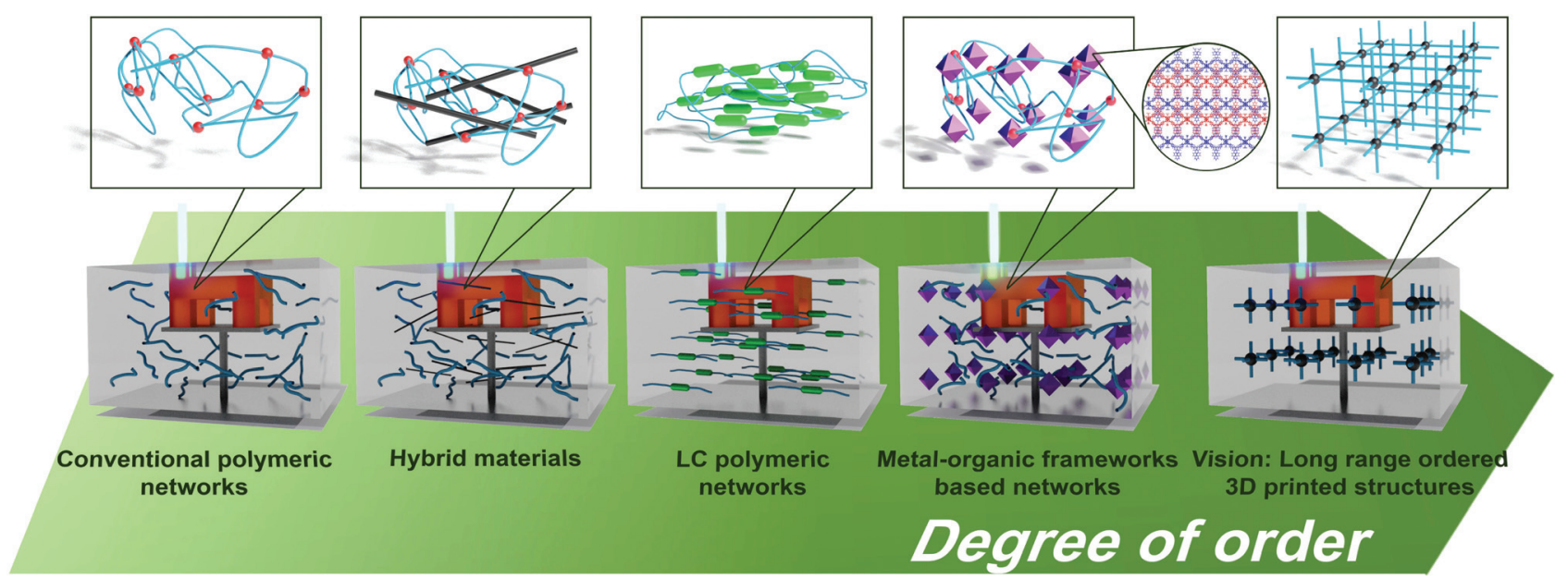

Fig. 1 Schematic representation of 3D printable materials used in light-triggered AM. From left to right (increasing degree of order), conventional polymeric networks, hybrid materials, liquid crystalline polymeric networks, networks containing MOF particles and a visual representation of a perfectly ordered MOF obtained after photocrosslinking. Polymers and their precursors are drawn in light blue, crosslinking points are represented as red spheres, microfibers as black rods, the LC mesogens as light green rods, MOF particles as purple octahedra and metal centres of the MOF as black spheres. The structure of Cu-BTB MOF was computed using crystallographic data from ref. 85, ccdc deposition nbr 708312.

above, a control of the internal structure enables the fabrication of structures exhibiting higher performances. Hybrid materials furnish a conceptually simple alternative to this issue. ${ }^{86}$

Hybrid (composite) materials refer, for polymeric matrices, (i) to designs making use of functional moieties of at least two different types. In such systems and in the context of stereolithography, two different monomeric functional groups are introduced in the photoresist. While a photopolymerisable group is used to enable the $3 \mathrm{D}$ printing of the material, a second functionalisation, innocent during the photoprinting process, is activated during a post-printing curing (thermal treatment, pyrolysis, chemical treatment, etc.), and provides the final material its specific characteristics. Chemically, while the photoresponsive functionalisation usually consists in (meth)acrylate groups, a broad variety of compounds can be used in post-printing cured functionalisation. Indeed, it can for example consist of a functional monomeric group of a different type, leading, by the polymerisation of the second polymeric backbone during curing, to highly crosslinked and highly entangled dual polymeric networks, ${ }^{87}$ or can consist of a ceramic from which a glassy or metallic material can be recovered through post-printing curing. ${ }^{88-94}$ (ii) Hybrid polymeric materials can also refer to matrices finally containing at least two microphases of different types, as, for example, to mechanically strong fibres (such as glass fibres, carbon fibres, or nanocellulose) dispersed in a polymeric matrix, ${ }^{95-101}$ or to nanocrystalline moieties covalently embedded within the final structure of the polymeric material.

In this section, we focus on a hybrid system for which the property enhancement arises (i) from the embedding of highly ordered nanocrystalline phases which do not show any particular ordering on the macroscale and (ii) the alignment of microfibers on the macroscale. Also, we will present some hybrid materials which were successfully employed in the formulation of photoresists for light-triggered AM. For readers interested in further details about mechanically reinforced composite materials for AM from a broader point-of-view, we recommend other dedicated review works. ${ }^{35,99,100,102-104}$

\subsection{Cellulose-based hybrid materials}

Cellulose is of particular interest as it can be obtained from renewable sources and takes part in the development of green chemical processes. Cellulose is obviously known for its material reinforcement abilities, as it is in nature, among other compounds, responsible for the mechanical strength of wood and other vegetal tissues.

Crystalline cellulose exists as cellulose nanocrystals (CNCs), cellulose nanofibrils (CNFs) or microfibrillated cellulose (MFC), with increasing particle dimensions, from (diameter $\times$ length) $10^{0}-10^{1} \mathrm{~nm} \times 10^{2}-10^{3} \mathrm{~nm}$ for CNCs to $10^{1}-10^{2} \mathrm{~nm} \times$ $\mu \mathrm{m}$ for MFC. ${ }^{105,106}$ MFC and CNFs, most likely due to the bigger particle size, are only employed in the context of material extrusion AM, while research on cellulose-based inks for light-triggered AM usually employs CNCs. ${ }^{107,108}$ Cellulosebased photoresists consist of either of the photopolymerisable matrices containing additive CNCs, yielding crosslinked materials with embedded CNCs after photoprinting. In this case, the CNC particles interact with the surrounding matrix through non-covalent interactions. Also, they can consist of CNC cores, decorated with functional groups that are non-innocent with respect to photopolymerisation, yielding materials where CNCs are covalently introduced in the polymeric structure through photocrosslinking. Although more synthetically challenging, this last strategy leads to materials depicting greater mechanical, thermal and chemical resistance.

Palaganas et al. ${ }^{109}$ detailed the effect of the reinforcement of polyethylene glycol diacrylate (PEGDA) with CNCs (Fig. 2I), introduced as additives with loadings ranging from $0 \mathrm{wt} \%$ to 

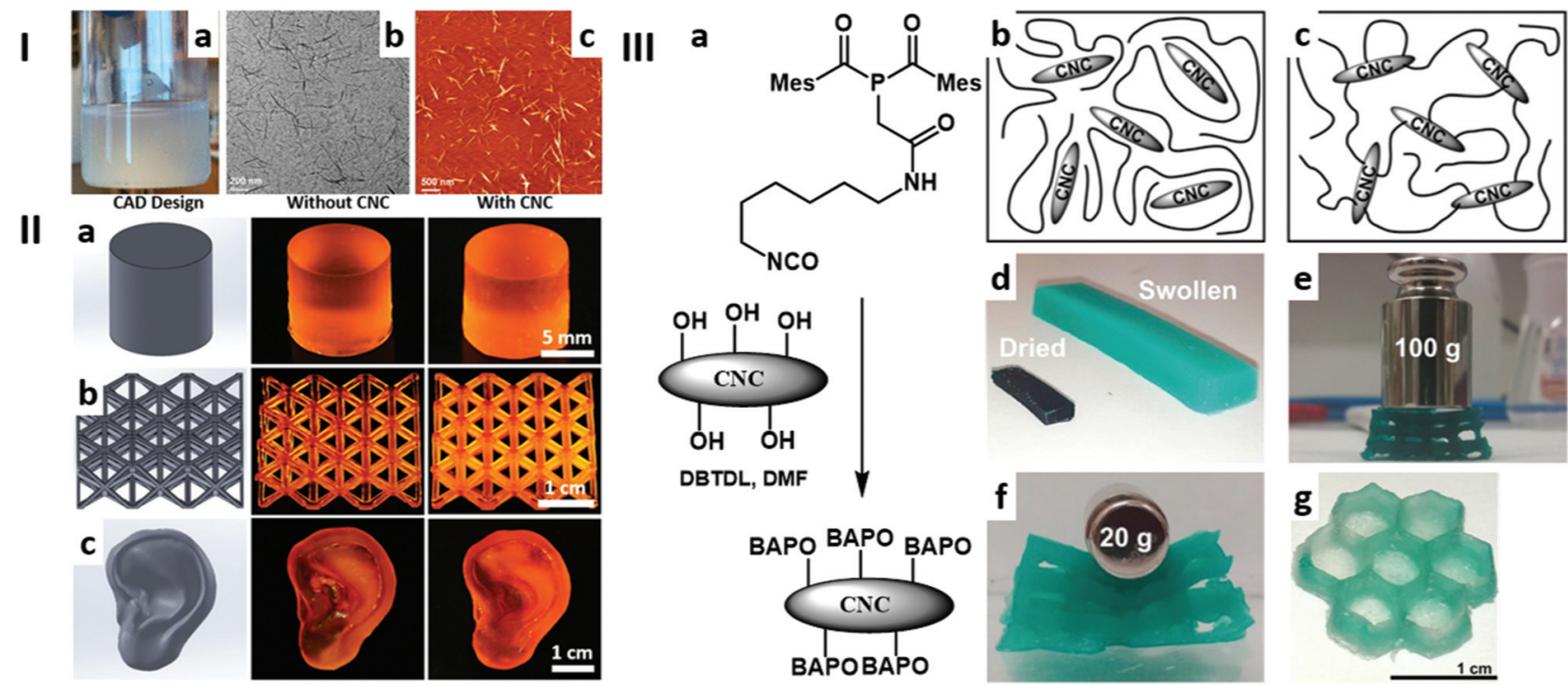

Fig. 2 Examples of cellulose containing 3D printed materials. I: (a) CNCs redispersed in water. (b) TEM and (c) AFM images showing CNCs with diameters of $3 \pm 1 \mathrm{~nm}$ and lengths of $246 \pm 100 \mathrm{~nm}$. Adapted from ref. 109 with permission from the American Chemical Society, Copyright $\odot$ 2017. II: (a) A disk structure, (b) an octet-truss lattice structure, and (c) an ear model. In the first column are shown the SolidWorks designs; in the second column, the DLP 3D printed structures that are printed from the matrix resin without any CNC addition; and in the third column the corresponding 3D structures that are printed from $1 \mathrm{wt} \% \mathrm{CNCs}$ incorporated into the matrix resin. Adapted from ref. 106 with permission from Springer Nature, Copyright $\odot$ 2019. III: (a) Synthesis of CNC-BAPO by urethane bond formation, Mes = mesityl $=2,4,6-\mathrm{Me}_{3} \mathrm{C}_{6} \mathrm{H}_{2}$. Schematic representation of the $\mathrm{CNC}$ /polymer composite after photopolymerisation for (b) neat CNCs and (d) CNC-BAPO. (d) Flat specimen generated from CNC-BAPO (7 wt\%). (e) A dried cubic-lattice structure from CNC-BAPO $(7 \mathrm{wt} \%)$ and $(\mathrm{f})$ the same structure after swelling for $1 \mathrm{~h}$. (g) A swollen hexagonal structure from CNC-BAPO (14 wt\%). Adapted from ref. 112 with permission from Wiley-VCH Verlag GmbH \& Co. KGaA, Weinheim, Copyright $\odot 2018$.

$1.2 \mathrm{wt} \%$. Crosslinked specimens were obtained by SLA with a $50 \mu \mathrm{m}$ resolution, and characterised noticeably by their mechanical properties. As a general trend, it was found that increasing CNC loading gradually enhances the material properties of the composite up to a threshold at around $0.3 \mathrm{wt} \%$ loading. On the other hand, increasing the CNC loading to $0.5 \mathrm{wt} \%, 0.9 \mathrm{wt} \%$ and $1.2 \mathrm{wt} \%$ had, overall, a negative effect upon the materials properties. The optimal fracture energy obtained in the context of this study ( $c a .3600 \mathrm{~J} \mathrm{~m}^{-2}$ ) was higher than that of natural cartilage $\left(1102 \pm 136 \mathrm{~J} \mathrm{~m}^{-2}\right)^{110}$ or than that of a similar material printed by direct ink writing (DIW) $\left(1500 \mathrm{~J} \mathrm{~m}^{-2}\right) .{ }^{111}$

By using a 1:1 PEGDA:1,3-diglyceroate diacrylate (DiGlyDA) matrix, Li et al. ${ }^{106}$ were able to obtain photoresists for SLA with suitable viscosity while having a CNC loading up to $5 \mathrm{wt} \%$. UV-vis transmittance analysis highlighted that the presence of DiGlyDA enhances the dispersibility of CNCs in the matrix, by introducing a competing H-bonding species that limits the agglomeration of CNCs. However, although the loading threshold for optimal mechanical properties was higher in this report than in previous studies, ${ }^{109}$ the optimal material properties were still observed with CNC loadings lower than $1 \mathrm{wt} \%$. The printed 3D structures investigated in this work are shown in Fig. 2II.

Wang et al. ${ }^{112}$ used a different approach, where they functionalised the surface of CNCs with Bis(acyl)phosphane oxides (BAPOs) photoinitiating functional groups (Fig. 2IIIa). The decorated CNC (CNC-BAPO) cores were further able to initiate the photocrosslinking of polyethylene glycol methyl ether methacrylate (PEGMEM), leading to a hydrogel in which CNCs are covalently introduced in the polymeric matrix (Fig. 2IIIc). The effective inclusion of the CNC cores within the polymeric structure was supported by the insolubility of these materials in water, contrarily, the hydrogel containing neat CNCs as additives (Fig. 2IIIb) or the pure PEGMEM hydrogel totally disintegrated while sonication for $1 \mathrm{~min}$ after $1 \mathrm{~d}$ of exposure to an aqueous medium. The Young's modulus of the material was characterised as a function of CNC-BAPO loading, which showed a Young's modulus of $270 \pm 10 \mathrm{MPa}$ and $340 \pm 25 \mathrm{MPa}$ for CNC-BAPO loadings of $3.27 \mathrm{wt} \%$ and $6.14 \mathrm{wt} \%$, respectively. In comparison, the pure PEGMEM hydrogel and the hydrogel with neat CNCs (2.54 wt\%) showed Young's moduli of $130 \pm 38 \mathrm{MPa}$ and $272 \pm 20 \mathrm{MPa}$, respectively. The materials showed reversible swelling capabilities of up to $1100 \%$, with great shape-integrity. Finally, the studied hydrogels were successfully used as photoresists for DLP, without a significant loss in mechanical performances compared to the cast samples previously characterised, Fig. 2IIId-g.

Pure cellulose-based photoresists have also been transferred to two-photon 3D laser printing by Rothammer et al. ${ }^{113}$ In their work, the authors used methacrylated cellulose diacetate, as a solution in acetone (800 wt\%), which was successfully printed at $780 \mathrm{~nm}$ with a resolution of $750 \mathrm{~nm}$ and feature size of $430 \pm 40 \mathrm{~nm}$ in the lateral direction. This is, to the best of our knowledge, the only example of a cellulose-based photoresist for two-photon $3 \mathrm{D}$ laser printing. 


\subsection{Hybrid materials based on carbon nanotubes (CNTs)}

Already observed and described from the $40 \mathrm{~s},{ }^{114-116}$ CNTs are pictorially needle-shaped rolls of graphene-sheets, which can be produced as multiple wall carbon nanotubes (MWCNTs) or as single wall carbon nanotubes (SWCNTs). Due to their outstanding intrinsic properties, noticeably regarding their electrical and thermal conductivity as well as their tensile strength ${ }^{117}$ and light weight, carbon nanotubes (CNTs) are of remarkable interest for the development of novel materials. ${ }^{118}$ With AM fabricated CNT/polymer composite materials having unequalised potential for the aerospace industry, ${ }^{119}$ medical purposes, ${ }^{120}$ as 4D materials, ${ }^{121}$ etc. Effectively, CNT/polymer composite materials address the issue of the brittleness of pieces produced by AM, but also allow the fabrication of polymeric materials with unprecedented electrical and thermal conductivity. Moreover, the introduction of anisotropy within such materials can lead to a directional amplification of these properties.

$\mathrm{CNT} /$ polymer composites have been successfully 3D printed employing material extrusion AM techniques. Those offer several advantages for the fabrication of CNT/polymer composite materials; noticeably, (i) the setup is usually more simple than phototriggered AM. (ii) CNTs are easily aligned by the shearing force applied by the nozzle. (iii) The issue arising from the light-scattering of the CNTs does not have to be addressed, thus allowing greater CNT loadings. Notwithstanding, the homogeneous dispersion of CNTs within the polymer matrix becomes then limiting and usually does not permit loadings greater than ca. $5 \mathrm{wt} \% .^{122}$ In addition, CNTs tend to damage the extrusion nozzle. ${ }^{123}$ Light-triggered AM offers, as presented previously, the opportunity to fabricate pieces with better surface resolution and smoothness as well as the opportunity to fabricate pieces on the microscale. Hence, there is still an important potential of CNT composite materials in this context. To mention some results, the electrical conductivity of a PEGDA:PEGMEM matrix went from 2.00 $10^{-11} \mathrm{~S} \mathrm{~m}^{-1}$ to $2.0010^{-7} \mathrm{~S} \mathrm{~m}^{-1}$ for CNT loadings ranging from $0 \mathrm{wt} \%$ to $0.5 \mathrm{wt} \%$, respectively. ${ }^{124}$ Furthermore, electrical conductivities up to $0.025 \mathrm{~S} \mathrm{~m}^{-1}$ were measured for a $0.3 \mathrm{wt} \%$ MWCNT/acrylate matrix composite material. ${ }^{125}$ SWCNT/ polymer composite photoresists were also successfully implemented in two-photon 3D laser printing with a definition of $c a .200 \mathrm{~nm},{ }^{126}$ and were evidenced, by Raman spectroscopy, to be self-aligned during the printing process. ${ }^{127}$

In 2016, Xiong et al. ${ }^{128}$ performed an extensive study of MWCNT/polymer composite materials for two-photon 3D laser printing, Fig. 3Ia-c. Noticeably, the authors evidenced the self-

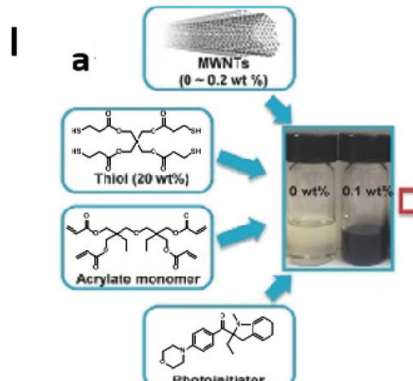

Preparation of composite resin

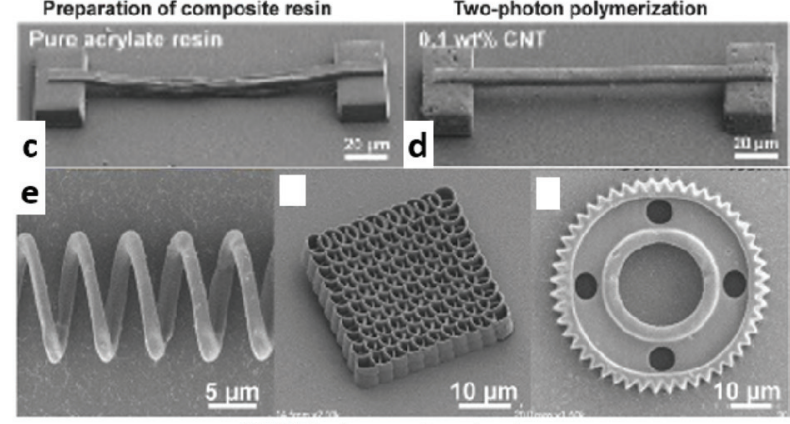

MWNT/polymer microstructures
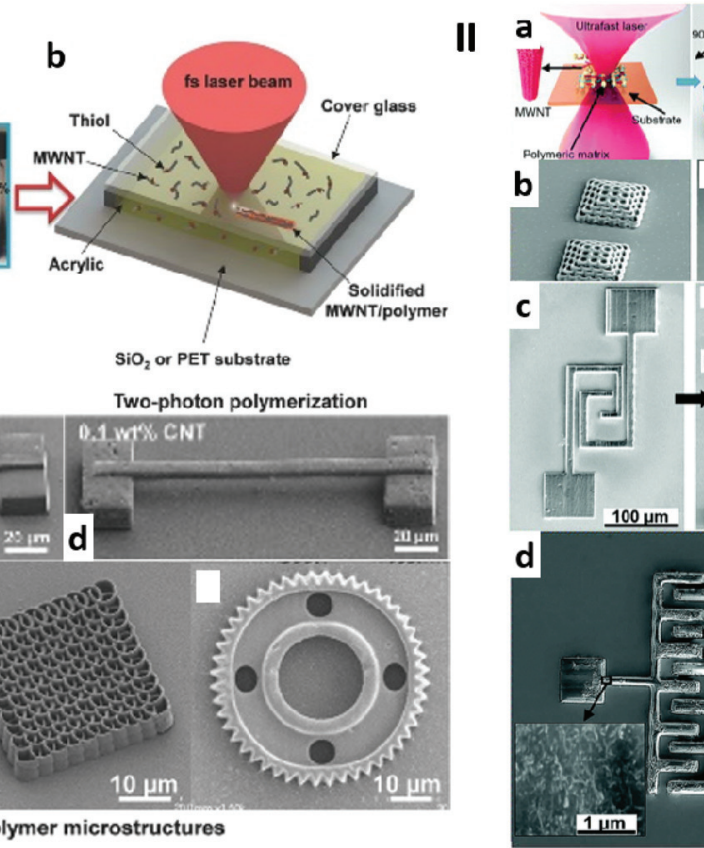
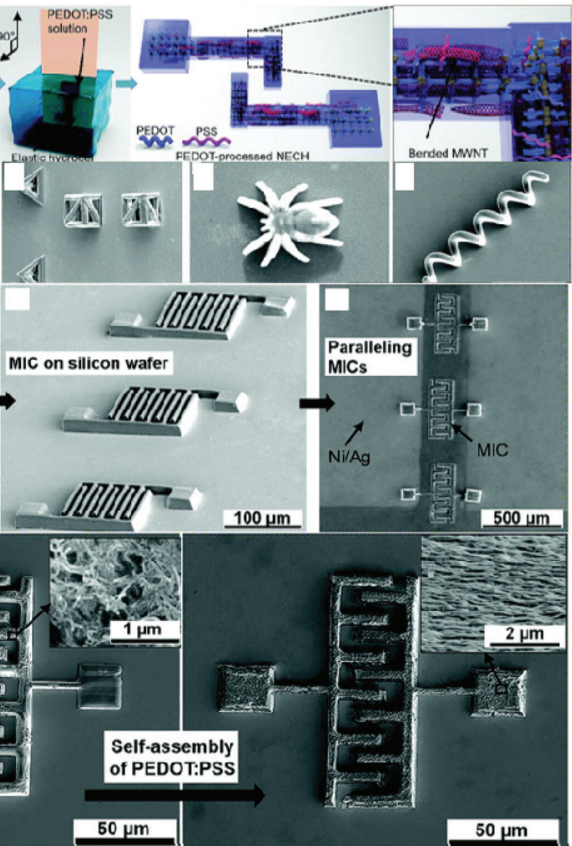
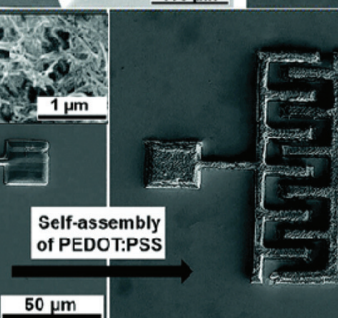

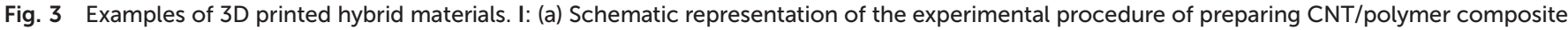

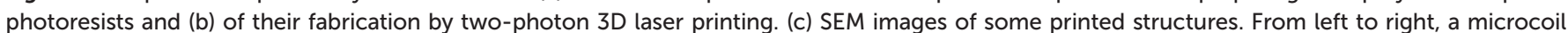

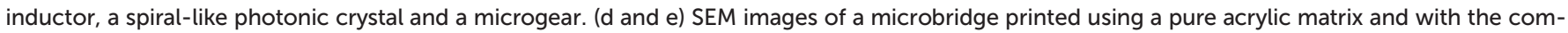

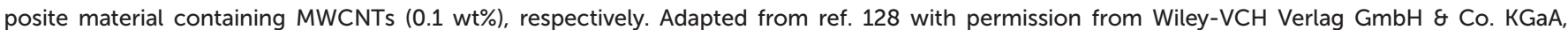

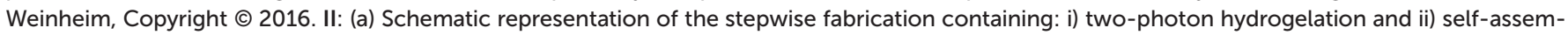

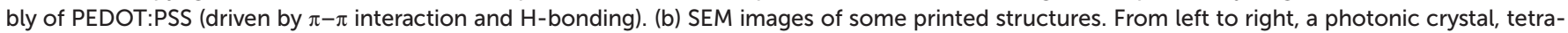

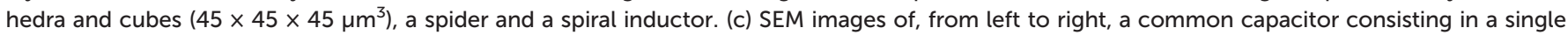

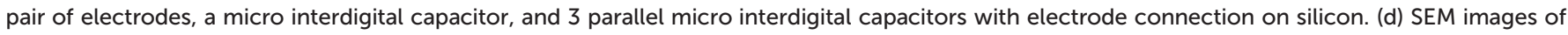

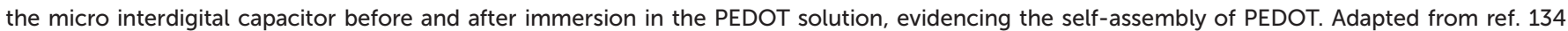
with permission from the Royal Society of Chemistry, Copyright @ 2019. 
alignment of MWCNTs under the influence of the laser beam irradiation. This alignment was proposed to arise from the strong electric field locally generated by the MWCNTs when irradiated with a high-intensity fs-laser beam. ${ }^{122}$ Thanks to the enhanced shape integrity and mechanical resistance provided by the alignment of the CNTs, large, complex and/or challenging 3D-structures could be fabricated (Fig. 3Ic and d). Finally, the good electrical conductivity of the CNT-polymer composite, $46.8 \mathrm{~S} \mathrm{~m}^{-1}$ with a $0.3 \mathrm{wt} \%$ MWCNT loading (much higher than values obtained in other reports ${ }^{129}$ ), motivated its use for the fabrication of micro-scale devices such as capacitors and resistors.

Greenhall and Raeymaekers ${ }^{130}$ demonstrated that Ni-coated CNTs were successfully aligned using ultrasonic waves. In their work, the authors constructed a specific vat for SLA manufacturing purposes. By surrounding the $30.2 \mathrm{~mm}$ vat with eight ultrasound transducers disposed in an octagon, the fibrils were selectively aligned at $0^{\circ}, 45^{\circ}, 90^{\circ}$ and $-45^{\circ}$, using the facing transducers in pairs and achieving an alignment along the direction perpendicular to the wave propagation. The manufacturing setup reported in this work allowed, among others, the fabrication of strong Bouligand 3D structures. Moreover, the authors demonstrated the power of the directed self-assembly-SLA procedure to fabricate composite materials with enhanced conductive behaviour. This behaviour was characterised by computing the electrical resistance within a $1 \mathrm{~mm}$ section of the material along or across the director vector. The $59.7 \pm 14.5 \Omega$ and $112 \pm 23.2 \mathrm{M} \Omega$ resistances computed from the $I / V$ measurements along the two directions, respectively, shows that Ni-coated CNTs increase the conductivity of the material, and that individual micro-wires appear to be insulated one from another in a direction perpendicular to the alignment.

Poly(3,4-ethylenedioxythiophene) (PEDOT):polystyrene sulfonate (PSS) is a well-known polymeric semiconductor, used for example as the hole-transporting material in perovskite solar cells. ${ }^{131-133}$ Tao et al. ${ }^{134}$ utilised PEDOT:PSS to dope a 3D printable MWCNT/acrylated matrix composite ink. Twophoton 3D laser printing was used for gelation, achieving 3D structures with a $200 \mathrm{~nm}$ definition. A schematic representation of the composite material and images of the printed structures are proposed in Fig. 3II. The embedded MWCNTs were shown to provide the tertiary composite material with an increased stiffness (Young's modulus up to $900 \mathrm{MPa}$ ), while decreasing the elongation at break from ca. 200\% at $<0.05 \mathrm{wt} \%$ MWCNT loading to $130 \%$ at 0.15 wt $\%$ MWCNT loading and yielding a brittle material at higher loadings. Most importantly, MWCNTs had a positive effect on the electrical conductivity of the material $\left(0.0007 \mathrm{~S} \mathrm{~m}^{-1}\right.$ at $0.05 \mathrm{wt} \%, 0.12 \mathrm{~S} \mathrm{~m}^{-1}$ at $0.2 \mathrm{wt} \%$ and $0.8 \mathrm{~S} \mathrm{~m}^{-1}$ at $0.3 \mathrm{wt} \%$ ), while the self-assembly of PEDOT further improved the electrical conductivity by an order of magnitude. Caused by the reactivity of PEDOT:PSS with polar solvents, the electrical conductivity of the crosslinked material could be tuned by putting it in contact with alcohols (methanol, ethanol, glycol and D-sorbitol), leading to potential application for alcohol sensing.
The investigation of the electrical conductivity of $3 \mathrm{D}$ printed PEDOT:PSS polymer composites proposed by Heo et $a .^{135}$ highlighted the positive impact of the embedded PEDOT:PSS independently to CNTs, as the system described in this work did not make use of CNTs, unlike the system proposed by Tao et al. ${ }^{134}$ Once again, the presence of an alcohol, ethylene glycol (EG) here, leads to a drop in the electrical resistance of the material containing EG $\left(662.0 \pm 100.6 \Omega \mathrm{sq}^{-1}\right)$ compared to the $0.91 \%$ PEDOT:PSS hydrogel $(968 \pm 245.1 \Omega$ $\mathrm{sq}^{-1}$ ). This effect was again attributed, in accordance to previous works, ${ }^{136,137}$ to the re-alignment of the PEDOT:PSS fibres in the presence of EG.

Besides, though CNT/polymer composite materials are promising as printable functional materials, there is still room for improvement until they can fulfill the requirements for their broader implementation on an industrial scale. ${ }^{120}$ Importantly, the ability to obtain well-dispersed stable suspensions of the CNTs within the matrix is one of the main challenges limiting their reproducibility and application on larger scales.

\section{Self-assembled materials}

Self-assembly is globally present in natural systems (examples are proteins, DNA, protein expression, lipid membrane bilayers in cells, etc.) and is the trigger for the good functioning of these systems. The direct inclusion of such biomacromolecular systems within photoresists can open a way towards biocompatible photocrosslinked polymeric materials. ${ }^{138-141}$ For example, as reported by Zhao et al. ${ }^{142}$ the selective self-assembly of DNA strands can be used for the design of printable hydrogels with a selective crosslinking density, having the biomacromolecular systems as a source of physical secondary crosslinking. Notably, such designs can provide the materials with $\mathrm{pH}$, thermal and binder selectivity. Also, Kim et al. ${ }^{143}$ successfully reported a bioink from silk fibroin in DLP for tissue engineering applications. In particular, methacrylate functionalised fibroin was used to fabricate organ structures, such as heart, vessel, brain, trachea and ear with excellent structural stability and good biocompatibility.

In another approach, biomimetically transposing the working concepts of these systems to synthetic polymeric materials is a promising pathway for the development of novel functional materials. Self-assembled synthetic materials such as amphiphilic block copolymers, liquid crystals or metallopolymers, among others, are potential candidates for this purpose. ${ }^{144-148}$

In the context of AM, out of the most noticeable selfassembled materials are liquid crystalline materials, and particularly nematic liquid crystals (NLCs). NLC mesophases are composed of stiff rod-shaped (calamitic) mesogens that align within the mesophases along a preferential director vector. Their ordering can be driven by phase segregation, by low-energy intermolecular interactions (such as hydrogen bonding, metal coordination, van der Waals forces or $\pi-\pi$ interactions), by the limitation of voids in the bulk, or by the coexistence of the latter driving forces. ${ }^{149}$ 
An undeniable example of highly ordered self-assembled synthetic materials is metal-organic frameworks (MOFs). Effectively, MOFs' crystalline units (metal/metallic cluster centre-organic linker) can have up to a three-dimensional extension. As will be detailed, this particular constitutive structure provides them with unique properties which can be transferred to polymeric materials by embedding MOFs in printable matrices.

In this section, we aim to describe recent examples where both self-assembly (bottom-up) and light-triggered AM (top-down) approaches have been merged, enabling the 3D printing of complex and functional structures exhibiting a clear hierarchical order. In particular, we will pay attention to printable liquid crystalline polymeric materials and MOF/polymer systems.

\subsection{Liquid crystalline materials}

First described by Finkelmann et al. in 1978, ${ }^{150,151}$ nematic liquid crystal (NLC) materials are well-known self-assembled materials exhibiting a relatively high degree of order. ${ }^{152-158}$ They are of great interest, as the averaged orientation along a director vector gives rise to intrinsic features such as optical properties, ${ }^{159-165}$ or macroscopic response to external stimuli. ${ }^{166-168}$ As NLCs are engendered by low-energy interactions, their alignment can be altered, generally by a temperature increase. The increasing randomness in the arrangement of the bulk commonly results in a spatial constriction along the formal director vector, as well as in an associated elongation along the directions normal to it. Most importantly, NLC materials can, after relaxation, recover their initial shape through the reappearance of a director vector. Acrylate-based NLC photoresists being commercially available supports their broad utilisation as a benchmark for the transfer of LC materials to light-triggered AM technologies.

The initial alignment of NLC-based photoresists can be achieved using a previously printed template, ${ }^{169-171}$ along the rubbing direction, ${ }^{172}$ under the influence of an external magnetic field, ${ }^{173}$ or under the influence of an external electric field. ${ }^{174,175}$ Furthermore, crosslinking of the monomeric functional groups was shown to efficiently freeze the alignment observed in the photoresist. Visual evidence for the alignment of NLC mesophases along an external electric field was provided by Yoshida et al. ${ }^{176}$ In addition, this study evidenced that (i) the orientation of the NLC was frozen by crosslinking and (ii) the shape of the investigated platelets does not impact their preferred orientation under the influence of an external electric field.

Due to the importance of achieving a controlled orientation to fully exploit the potential of NLC materials, they are, in the context of AM, usually studied using two-photon 3D laser printing, DIW ${ }^{177}$ or mask lithography. ${ }^{178}$ In other words, AM techniques that do not require the photoresist to have a low viscosity (while this is an important requirement for SLA, DLP and CLIP). As a matter of fact, besides the notable reports of Ullett et al., ${ }^{173,179}$ who reported the 3D printing of NLC materials by SLA using a highly specific setup, the 3D printing of NLC materials by conventional DLP or SLA technology remains inaccessible to date. In the later mentioned works, the alignment of NLC mesogens was achieved by applying an external magnetic field to a mini-vat, using a surrounding $0.32 \mathrm{~T}$ magnet. And an alignment of the NLC mesophases was indirectly demonstrated by attributing a directional anisotropy in the glassy state elastic modulus and the tensile strength to the anisotropically oriented nematic mesophases. Nevertheless, the complexity of the process (and its associated limitations) justifies the lack of popularity of SLA for the processing of NLC materials after this example.

Wiersma and co-workers intensively studied NCL microstructures printed by two-photon laser lithography from a photoresist formulated with a mono acrylated reactive mesogen, [4-(6-(acryloyloxy)hexyl)oxy)phenyl] 4-methoxybenzoate, 78 mol\%; RM257 as the crosslinker, 4-(3-acryloyloxypropyloxy)benzoesure 2-methyl-1,4-phenylester, $20 \mathrm{~mol} \%$; an azobenzene monoacrylate, (E)-6-((4-((2-cyano-4-nitrophenyl)diazenyl)phenyl)(ethyl)amino)hexyl acrylate, $1 \mathrm{~mol} \%$; and Irgacure 369, $1 \mathrm{~mol} \%$. The corresponding chemical structures are shown in Fig. 4Ia. In particular, the authors studied the mechanism for the observed swelling of the material during printing, ${ }^{180}$ the kinetics of the light-responsivity of the material ${ }^{181}$ and the effect of the medium on their spatial responsivity. ${ }^{182}$ The group also demonstrated the potential and the versatility of their material by proposing innovative designs for microfabricated devices. Among them, a photonic microhand with high wavelengthselectivity for folding and a light-fuelled microscopic walker are worth mentioning. ${ }^{183,184}$ In $2018,{ }^{185}$ the group proposed the implementation of the same material for the construction of dual rigid/soft polymeric photonic circuits, tuneable by light. A $90^{\circ}$ bend polymeric waveguide terminated by a grating coupler at both ends, as well as an anchoring structure for a whispering gallery mode resonator (WGMR) was constructed using a neutral photoresist. The light-responsive NLC material was used during a second printing step to provide the WGMR its light tunability. In the first design, the WGMR (free spectral range of $12.5 \mathrm{~nm}, n_{\text {eff }}=1.52$, and $Q_{\text {calc }}=80000$ ) was itself made out of the light-responsive material and was designed as a ring, while the second design consists in an Ip-Dip ringshaped WGMR, topped with a NLC cylinder, which can alter the WGMR geometry by mechanical deformation under light irradiation, Fig. 4Ib and c. As the wavelength selectivity of WGMRs depends on their outer circumference (i.e. resonance will occur if the outer circumference is an integer multiple of the propagated wavelength), their wavelength selectivity could be tuned by varying the outer circumference of the WGMR. Hence, the authors could tune the wavelength selectivity of the proposed WGMR by up to $-3.7 \mathrm{~nm}$ and $+11.5 \mathrm{~nm}$ for the first and the second designs, respectively. E7, ${ }^{186,187}$ supplied by Merck ${ }^{\circledR}$, is a NLC mixture that has been broadly used by the scientific community. Noticeably, the group of Elston $^{174,175,188,189}$ investigated its use for 3D laser lithography. In the context of light-triggered AM, E7 is generally used together with one or several reactive mesogen(s), such as RM257 mentioned previously, responsible for crosslinking. ${ }^{190}$ 

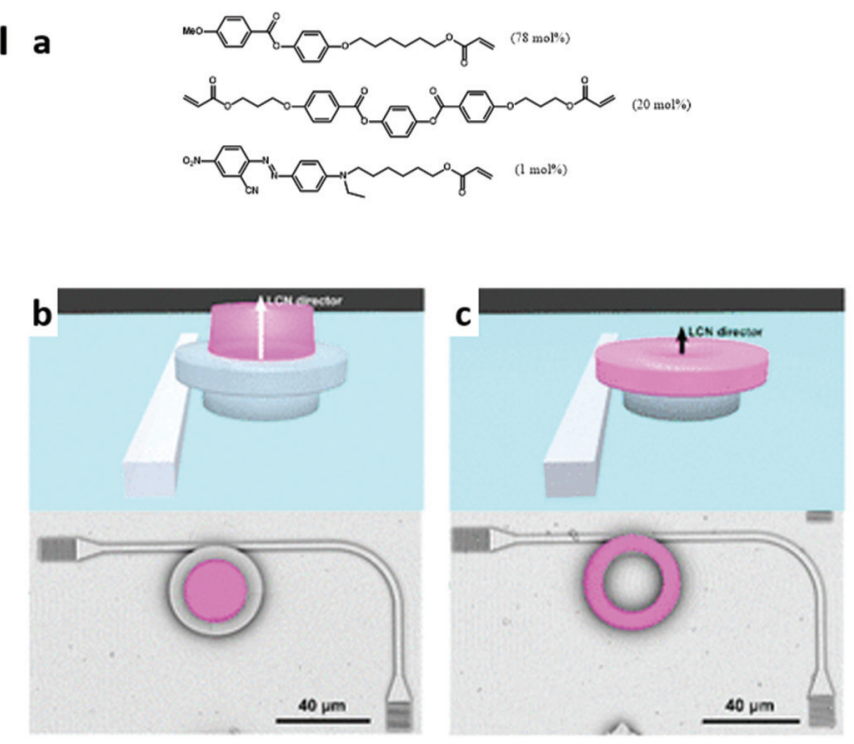
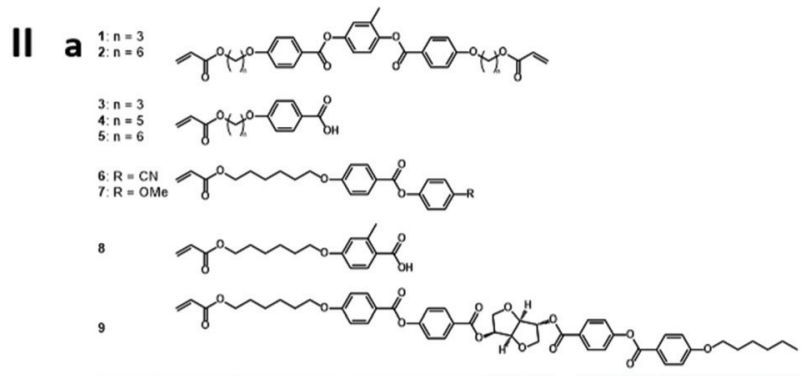

b
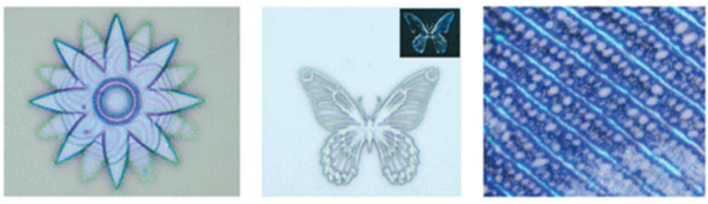

c
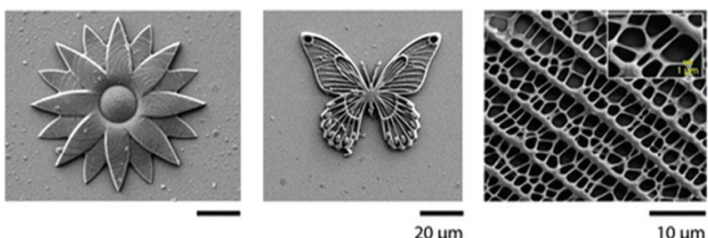

Fig. 4 Examples of 3D printed liquid crystalline microstructures. I: (a) Chemical structures of the NLC compounds used in the formulation of the photoresist and the formulation ratio. (b) Rendering and SEM image (top view, false colour for the NLC element) for the design consisting of a WGMR out of IP-Dip, topped with a light-responsive actuator of NLC ink (second design). (c) Rendering and SEM image (top view, false colour for the NLC element) for the design consisting of a WGMR made out of the light-responsive NLC ink (first design). Adapted from ref. 185 with permission from the American Chemical Society, Copyright ( $)$ 2018. II: (a) Chemical structures of the NLC compounds used in the formulation of the photoresist. (b) Optical microscopy and (c) SEM images of the printed structures. From left to right, a flower, a butterfly and the biomimetic pattern of the wing of the Papilio Paris butterfly. Adapted from ref. 191 with permission from the American Chemical Society, Copyright @ 2020.

Recently, Del Pozo et al. ${ }^{191}$ used a 9-component mixture of mono- and di-acrylated NLC mesogens which was processed by two-photon 3D laser printing with a minimum feature size of around $200 \mathrm{~nm}$, (Fig. 4II). In the design of this system, the H-bonding participating in the stability of NLC mesophases could be broken by basic treatment. The obtained photonic material thereafter depicts a colour change and swelling in the presence of humidity. Indeed, the basic treatment leads to the formation of a hygroscopic polymer, allowing the uptake of water vapour. Moreover, temperature treatment was shown to reversibly recover the initially non-hydrated state of the material. While total dehydration was observed from $70{ }^{\circ} \mathrm{C}$, the reversibility of the swelling was successful over ten cycles under $75 \%$ relative humidity $(\mathrm{RH})$ with temperatures varying between $25{ }^{\circ} \mathrm{C}$ (12-18\% expansion) and $20{ }^{\circ} \mathrm{C} \quad(25-30 \%$ expansion). Correspondingly, a slight colour change was observed in the same temperature range at $75 \% \mathrm{RH}$, while a clear light-blue to bright-green colour sweep was observed from $18{ }^{\circ} \mathrm{C}$ to $16{ }^{\circ} \mathrm{C}$ at $75 \% \mathrm{RH}$.

In 2019, Chen et al. ${ }^{192}$ reported a novel strategy for the preparation of light-responsive materials, whose photoresponsivity was not based on the common azobenzene moiety. ${ }^{193}$ Instead, the authors used a nanocomposite photoresist composed of gold nanoparticles ( $3 \mathrm{wt} \%$ ) embedded in a C6BP : RM257 (88.2 : $9.8 \mathrm{~mol} \%$ ) matrix. In this system, the near infrared light irradiation of the printed structures engenders a local temperature increase caused by light-harvesting by the gold nanoparticles. The temperature increase finally induces a phase transition of the LC in the nematic state toward the isotropic state. As a result, the authors observed a spatial constriction along the director vector and a $20 \%$ length elongation perpendicular to the director vector. The process showed good reversibility as a relative $20 \%$ loss in elongation was observed over 300 cycles.

Although the majority of the publications in the field make use of commercial compounds in their formulations, some groups reported novel reactive mesogens in the past years. Sungur et $a{ }^{172}$ synthesised a novel monoacrylated reactive mesogen. Rectangular films were fabricated through a onephoton process, depicting a temperature-induced constriction along the director vector and elongation in the perpendicular direction.

\subsection{Metal organic framework based networks}

As mentioned previously, MOFs represent one of the most advanced examples of ordering achievable by self-assembly. MOFs are $1 \mathrm{D}$ - to 3D-extended crystalline compounds conventionally formed by the self-assembly of a metallic centre (usually a d-metal or a metallic cluster) and organic linkers. Out of many more factors their unique porosity and optical, adsorption, catalytic and magnetic properties explain the research interest they are attracting. ${ }^{194-198}$ Adapting such compounds to allow their processing by light-triggered $\mathrm{AM}$ has the potential to allow the 
fabrication of active materials of controlled macroscopic shape.

Magdassi and coworkers ${ }^{199}$ furnished, to the best of our knowledge, the single example of the embedding of MOF crystals in a polymer matrix by $3 \mathrm{D}$ printing. In this work, the authors dispersed $10 \mathrm{wt} \%$ copper benzene-1,3,5-tricarboxylate (Cu-BTC) MOF in a 2-phenoxyethyl acrylate:PEGDA photopolymerisable matrix, which was successfully printed into a flexible hydrogel by DLP, Fig. 5. Post-printing X-ray diffraction ana-
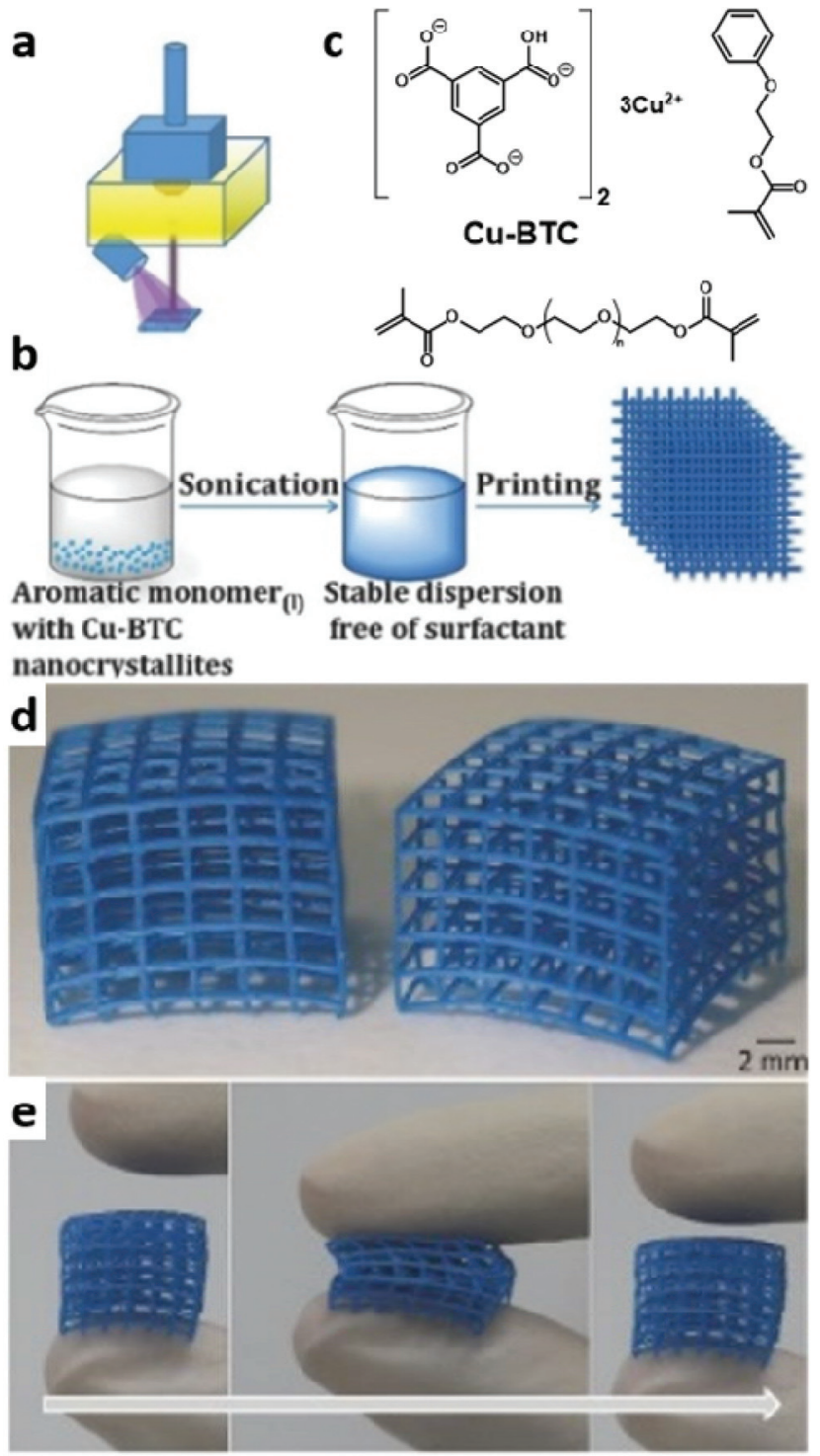

Fig. 5 (a) Representation of the DLP fabrication process. (b) Fabrication process of the photoresist containing an embedded Cu-BTC MOF. From left to right, the Cu-BTC crystals are dispersed in the matrix, the photoinitiator is added and the photoresist is printed by DLP. (c) Chemical structures of Cu-BTC, the monomer and the crosslinker. (d) 3D-printed cubic nets of the MOF-polymer composite. (e) Demonstration of the flexibility of the 3D-printed cubic nets. From left to right before, during and after pressing. The time axis is denoted by a grey arrow. Adapted from ref. 199 with permission from Wiley-VCH Verlag GmbH \& Co. KGaA, Weinheim, Copyright $\odot 2017$. lysis supported the stability of the crystalline structure of $\mathrm{Cu}$ BTC through photopolymerisation. The analysis of adsorptive capabilities, for the adsorption of methylene blue (MB), showed that the adsorptive capabilities of the printed structure were strongly dependent on their 3D design, as solely surface MOF particles apparently demonstrated adsorption activity. The comparison with pure Cu-BTC demonstrated the superior adsorptive capabilities of the latter $\left(0.75 \mathrm{mg} \mathrm{g}^{-1}\right)$ with respect to the MOF/polymer composite $\left(0.6 \mathrm{mg} \mathrm{g}^{-1}\right)$ over their exposure to an aqueous solution of $\mathrm{MB}$ for less than $2 \mathrm{~h}$. Notwithstanding, longer exposure times highlighted the greater performances of the MOF/polymer composite. Most likely, this arises from an increased stability, provided by the surrounding polymeric matrix, of the MOF-polymer composite in aqueous media compared to the pure MOF.

The same group used $\left[\mathrm{Cu}(\mathrm{TAcO})_{2}\left(\mathrm{H}_{2} \mathrm{O}\right)\left(4,4^{\prime} \text {-bipy }\right)\right]_{n} \cdot 2 \mathrm{H}_{2} \mathrm{O}$, a 1D metal-organic coordination polymer, together with dipropylene glycol diacrylate and diethylene glycol methyl ether, to fabricate, by DLP, 3D printed structures capable of moisture sensing. ${ }^{200}$ Effectively, the reversible substitution of the water ligand by a solvent molecule led to a colour change from blue to purple after substitution. The original is recovered after several minutes when exposed to ambient atmosphere. The material could then be used for moisture sensing in organic solvents, a colour change being indicative of an anhydrous solvent.

The group also developed a porous (surface area of $53.32 \pm$ $23.00 \mathrm{~m}^{2} \mathrm{~g}^{-1}$ and pore size of $\left.35.90 \pm 24.80 \AA\right)$ material $3 \mathrm{D}$ printed by DLP. ${ }^{201}$ For this purpose, the authors made use of $\mathrm{Ni}^{2+}$ complexes carrying acrylamide ligands. The analysis of the crosslinked materials evidenced that the coordination sphere of the $\mathrm{Ni}^{2+}$ metal centres remained unchanged through photopolymerisation. Although the strategy being used here does not permit the synthesis of perfectly ordered metalorganic extended compounds, the achievement of the processing of a metal-organic extended structure by DLP using a well-defined methacrylated Ni-complex is an important step forward.

The treated examples demonstrated that the activity of the MOF can be retained when MOF particles are dispersed in a photopolymerisable matrix and further processed. Although a slight decrease in activity can be expected, one can also expect an increase in chemical resistance of the embedded MOF particles. These studies open the road to the transfer of more diverse MOF species to light-triggered AM.

\section{Outlook and future perspectives}

In this perspective, we present an overview of the state of the art of 3D printable materials for light-triggered AM, exhibiting different degrees of ordering, in particular, hybrid materials containing CNTs or crystalline nanostructures as additives for the enhancement of the properties of printable polymers matrices, particularly regarding their mechanical, thermal and chemical resistance as well as their conductivity. Despite the 
great progress that has been made in the 3D printing of hybrid materials using light during the last years, the preparation of well-dispersed inks including higher loads of the additive within the polymeric matrix and its upscaling at competitive costs are the major challenges of the field. Also, examples of 3D printed structures from self-assembled materials based on liquid crystals and MOFs were discussed. Specifically, photoreactive inks based on liquid crystals have successfully been employed for the fabrication of functional devices such as light-tunable WGMRs and of 3D dynamic microstructures showing response to different stimuli, such as temperature, light or humidity. However, further efforts to improve these systems are still necessary. For example, the incorporation of novel stimuli-responsive mesogens (so far, the number of liquid crystalline monomers employed in $3 \mathrm{D}$ printing is very limited) and the control of their alignment in any desired direction would allow the preparation of 3D structures exhibiting a complex actuation, which are currently unattainable using conventional inks. Furthermore, MOF-based materials promisingly show the retention of the properties of the embedded MOF over an AM process and a good step towards the achievement of long-range ordered printed structures. In addition, the MOF/polymer composites were shown to have an enhanced chemical resistance compared to the pure MOF.

In summary, it was demonstrated that light-triggered AM is a versatile fabrication technique that not only enables a facilitated fabrication of personalised pieces, with complicated structures, or of structures that cannot be fabricated otherwise, but also that the limit of printable materials is far from being reached. By choosing pre-ordered materials as a guideline, novel functional structures with enhanced properties become possible. Indeed, hierarchically ordered materials can offer multiple opportunities in the emerging field of $4 \mathrm{D}$ printing for the fabrication of stimuli-responsive and chemically active materials. Furthermore, as already mentioned the variety of self-assembling materials currently being investigated in the context of light-triggered AM remains fairly narrow from a chemical point-of-view. We are though confident that, considering the extensive variety of self-assembled materials in nature (e.g. DNA, proteins, etc.) and functional polymers (e.g. amphiphilic block copolymers), many of these materials could be successfully transferred to lighttriggered AM.

We believe that merging the bottom-up molecular control of self-assembled materials with the versatility of 3D printing techniques has good prospects and will enable new opportunities for the design and realisation of 3D structures, whose properties can be controlled on demand. Thus, further efforts on the development of new polymeric printable materials exhibiting hierarchical order are essential and will have a great impact in the future of the field.

\section{Conflicts of interest}

The authors declare no conflict of interest.

\section{Acknowledgements}

The authors acknowledge funding from the Helmholtz program "Science and Technology of Nanosystems" (STN) and from the Deutsche Forchungksgemeinschaft (DFG, German research Foundation) under Germany's Excellence Strategy via the Excellence Cluster 3D Matter Made to Order (EXC-2082 390761711), and by the Carl Zeiss Foundation through the Carl-Zeiss-Focus@HEiKA.

\section{References}

1 E. E. Petersen and J. Pearce, Technologies, 2017, 5, 7.

2 R. Liu, Z. Wang, T. Sparks, F. Liou and J. Newkirk, in Laser Additive Manufacturing, ed. M. Brandt, Woodhead Publishing, 2017, pp. 351-371.

3 B. Lyons, Bridge, 2012, 42, 13-19.

4 M. Delic and D. R. Eyers, Int. J. Prod. Econ., 2020, 228, 107689.

5 J. Patalas-Maliszewska, M. Topczak and S. Kłos, Appl. Sci., 2020, 10, 735.

6 N. Nachal, J. A. Moses, P. Karthik and C. Anandharamakrishnan, Food Eng. Rev., 2019, 11, 123-141.

7 K. Qiu, G. Haghiashtiani and M. C. McAlpine, Annu. Rev. Anal. Chem., 2018, 11, 287-306.

8 J. Gardan, Int. J. Prod. Res., 2016, 54, 3118-3132.

9 S. C. Ligon, R. Liska, J. R. Stampfl, M. Gurr and R. Mülhaupt, Chem. Rev., 2017, 117, 10212-10290.

10 I. Gibson, D. Rosen and B. Stucker, Additive Manufacturing Technologies: $3 D$ Printing, Rapid Prototyping, and Direct Digital Manufacturing, Springer-Verlag, New York, 2015.

11 C. W. Hull, US4575330A, 1986.

12 T. D. Ngo, A. Kashani, G. Imbalzano, K. T. Nguyen and D. Hui, Composites, Part B, 2018, 143, 172-196.

13 M. Vaezi, H. Seitz and S. Yang, Int. J. Adv. Manuf. Technol., 2013, 67, 1721-1754.

$14 \mathrm{X}$. Luo, J. Li and M. Lucas, presented in part at the Laser 3D Manufacturing IV, 2017.

15 H. Jigang, Q. Qin, W. Jie and F. Hui, Int. J. Mater., Mech. Manuf., 2018, 6, 332-336.

16 T. Finnes, J. Undergrad. Res., 2015, 13, 3.

17 N. Fang, C. Sun and X. Zhang, Appl. Phys. A, 2004, 79, 1839-1842.

18 B. Msallem, N. Sharma, S. Cao, F. S. Halbeisen, H.-F. Zeilhofer and F. M. Thieringer, J. Clin. Med., 2020, 9, 817.

19 L. Yao, P. Hu, Z. Wu, W. Liu, Q. Lv, Z. Nie and H. Zhengdi, presented in part at the Journal of Physics: Conference Series, 2020.

20 S. Mansour, M. Gilbert and R. Hague, Mater. Sci. Eng., A, 2007, 447, 277-284.

21 J. Z. Manapat, Q. Chen, P. Ye and R. C. Advincula, Macromol. Mater. Eng., 2017, 302, 1600553.

22 X. Wang, M. Jiang, Z. Zhou, J. Gou and D. Hui, Composites, Part B, 2017, 110, 442-458. 
23 M. A. Matos, A. M. A. Rocha and A. I. Pereira, Int. J. Adv. Manuf. Technol., 2020, 1-13.

24 D. Miedzińska, E. Małek and A. Popławski, Appl. Comput. Sci., 2019, 15, 16-26.

25 D. Miedzińska, R. Gieleta and E. Małek, Mech. Mater., 2020, 141, 103245.

26 S. Razavi Bazaz, N. Kashaninejad, S. Azadi, K. Patel, M. Asadnia, D. Jin and M. Ebrahimi Warkiani, Adv. Mater. Technol., 2019, 4, 1900425.

27 Y. Yang, H. Li, Y. Xu, Y. Dong, W. Shan and J. Shen, Int. J. Pharm., 2019, 562, 66-75.

28 J. R. Tumbleston, D. Shirvanyants, N. Ermoshkin, R. Janusziewicz, A. R. Johnson, D. Kelly, K. Chen, R. Pinschmidt, J. P. Rolland, A. Ermoshkin, E. T. Samulski and J. M. DeSimone, Science, 2015, 347, 1349.

29 J. M. DeSimone, A. Ermoshkin, N. Ermoshkin and E. T. Samulski, US10016938B2, 2018.

30 J. Balli, S. Kumpaty and V. Anewenter, presented in part at the ASME 2017 International Mechanical Engineering Congress and Exposition, Tampa, Florida, USA, November 3-9, 2017.

31 J. R. Tumbleston, D. Shirvanyants, N. Ermoshkin, R. Janusziewicz, A. R. Johnson, D. Kelly, K. Chen, R. Pinschmidt, J. P. Rolland and A. Ermoshkin, Science, 2015, 347, 1349-1352.

32 R. Janusziewicz, J. R. Tumbleston, A. L. Quintanilla, S. J. Mecham and J. M. DeSimone, Proc. Natl. Acad. Sci. U. S. A., 2016, 113, 11703-11708.

33 J. W. Stansbury and M. J. Idacavage, Dent. Mater., 2016, 32, 54-64.

34 C. A. Spiegel, M. Hippler, A. Münchinger, M. Bastmeyer, C. Barner-Kowollik, M. Wegener and E. Blasco, Adv. Funct. Mater., 2019, 1907615.

35 M. Carlotti and V. Mattoli, Small, 2019, 15, 1902687.

36 H. B. Sun and S. Kawata, in Nmr - 3d Analysis Photopolymerization, Springer, 2004, vol. 170, pp. 169-273.

37 Y. L. Zhang, Q. D. Chen, H. Xia and H. B. Sun, Nano Today, 2010, 5, 435-448.

38 S. D. Gittard and R. Narayan, Expert Rev. Med. Devices, 2010, 7, 343-356.

39 J. Fischer and M. Wegener, Laser Photonics Rev., 2013, 7, 22-44.

40 W. Zapka, Handbook of Industrial Inkjet Printing: A Full System Approach, John Wiley \& Sons, 2017.

41 C. S. Sheppard and V. R. Kamath, Polym. Eng. Sci., 1979, 19, 597-606.

$42 \mathrm{H}$. Hageman, in Photopolymerisation and photoimaging science and technology, Springer, 1989, pp. 1-53.

43 S. Jockusch, M. S. Landis, B. Freiermuth and N. J. Turro, Macromolecules, 2001, 34, 1619-1626.

44 K. Dietliker, P. Murer, R. Hüsler and T. Jung, US9199934B2, 2015.

45 S. Jockusch and N. J. Turro, J. Am. Chem. Soc., 1998, 120, 11773-11777.

46 M. Haas, J. Radebner, A. Eibel, G. Gescheidt and H. Stueger, Chem. - Eur. J., 2018, 24, 8258-8267.
47 D. Bird, E. Caravaca, J. Laquidara, K. Luhmann and N. M. Ravindra, presented in part at the TMS 2019 148th Annual Meeting \& Exhibition Supplemental Proceedings, Cham, 2019.

48 K. C. Wong, E. Ng, W. T. Wong and P. Chiu, Chem. - Eur. J., 2016, 22, 3709-3712.

49 J. H. Ding and D. L. Gin, Chem. Mater., 2000, 12, 22-24.

50 E. Maron, J. H. Swisher, J. J. Haven, T. Y. Meyer, T. Junkers and H. G. Börner, Angew. Chem., Int. Ed., 2019, 58, 1074710751.

51 N. Zabarjad Shiraz, E. Enferad, A. Monfared and M. A. Mojarrad, ISRN Polym. Sci., 2013, 280897.

52 G. Jyoti, A. Keshav and J. Anandkumar, Int. J. Chem. React. Eng., 2016, 14, 571-578.

53 G. P. Monnier, P. Ciceron, C. M. Leroy and C. Bourrousse, US20170355660A1, 2019.

54 S. Juodkazis, V. Mizeikis, K. K. Seet, M. Miwa and H. Misawa, Nanotechnology, 2005, 16, 846.

55 V. Mizeikis, K. K. Seet, S. Juodkazis and H. Misawa, Opt. Lett., 2004, 29, 2061-2063.

56 J. M. McCracken, V. P. Tondiglia, A. D. Auguste, N. P. Godman, B. R. Donovan, B. N. Bagnall, H. E. Fowler, C. M. Baxter, V. Matavulj and J. D. Berrigan, Adv. Funct. Mater., 2019, 29, 1903761.

57 P. J. Bártolo and I. Gibson, Stereolithography: Materials, Processes and Applications, Springer US, Boston, MA, 2011.

58 S. K. Reddy, N. B. Cramer, M. Kalvaitas, T. Y. Lee and C. N. Bowman, Aust. J. Chem., 2006, 59, 586-593.

59 E. Blasco, M. Wegener and C. Barner-Kowollik, Adv. Mater., 2017, 29, 1604005.

60 T. Y. Lee, J. Carioscia, Z. Smith and C. N. Bowman, Macromolecules, 2007, 40, 1473-1479.

61 J. W. Chan, J. Shin, C. E. Hoyle, C. N. Bowman and A. B. Lowe, Macromolecules, 2010, 43, 4937-4942.

62 A. Oesterreicher, S. Ayalur-Karunakaran, A. Moser, F. H. Mostegel, M. Edler, P. Kaschnitz, G. Pinter, G. Trimmel, S. Schlögl and T. Griesser, J. Polym. Sci., Part A: Polym. Chem., 2016, 54, 3484-3494.

63 H. Leonards, S. Engelhardt, A. Hoffmann, L. Pongratz, S. Schriever, J. Bläsius, M. M. Wehner and A. Gillner, presented in part at the Laser 3D Manufacturing II, 2015.

64 S. Baudis, F. Nehl, S. C. Ligon, A. Nigisch, H. Bergmeister, D. Bernhard, J. Stampfl and R. Liska, Biomed. Mater., 2011, 6, 055003.

65 A. Oesterreicher, J. Wiener, M. Roth, A. Moser, R. Gmeiner, M. Edler, G. Pinter and T. Griesser, Polym. Chem., 2016, 7, 5169-5180.

66 G.-H. Wu and S.-H. Hsu, J. Med. Biol. Eng., 2015, 35, 285-292.

67 B. D. Fairbanks, T. F. Scott, C. J. Kloxin, K. S. Anseth and C. N. Bowman, Macromolecules, 2009, 42, 211-217.

68 A. B. Lowe, Polymer, 2014, 55, 5517-5549.

69 A. F. Senyurt, H. Wei, C. E. Hoyle, S. G. Piland and T. E. Gould, Macromolecules, 2007, 40, 4901-4909.

70 A. Concellón, A. P. Schenning, P. Romero, M. Marcos and J. L. Serrano, Macromolecules, 2018, 51, 2349-2358. 
71 E. Sato, S. Nagai and A. Matsumoto, Prog. Org. Coat., 2013, 76, 1747-1751.

72 J. He, Y. Zhao and Y. Zhao, Soft Matter, 2009, 5, 308-310.

73 S. R. Govindarajan, Y. Xu, J. P. Swanson, T. Jain, Y. Lu, J.-W. Choi and A. Joy, Macromolecules, 2016, 49, 24292437.

74 Q. Liu, T. Jain, C. Peng, F. Peng, A. Narayanan and A. Joy, Macromolecules, 2020, 53, 3690-3699.

75 V. T. Widyaya, E. K. Riga, C. Müller and K. Lienkamp, Macromolecules, 2018, 51, 1409-1417.

76 C. P. Kabb, C. S. O'Bryan, C. C. Deng, T. E. Angelini and B. S. Sumerlin, ACS Appl. Mater. Interfaces, 2018, 10, 16793-16801.

77 Y. L. Sun, W. F. Dong, R. Z. Yang, X. Meng, L. Zhang, Q. D. Chen and H. B. Sun, Angew. Chem., Int. Ed., 2012, 51, 1558-1562.

78 Y.-L. Sun, Z.-S. Hou, S.-M. Sun, B.-Y. Zheng, J.-F. Ku, W.-F. Dong, Q.-D. Chen and H.-B. Sun, Sci. Rep., 2015, 5, 12852.

79 N. Igarashi, S. Onoue and Y. Tsuda, Anal. Chem., 2007, 23, 943-948.

80 B. Kaehr and J. B. Shear, Proc. Natl. Acad. Sci. U. S. A., 2008, 105, 8850-8854.

81 B. Kaehr, R. Allen, D. J. Javier, J. Currie and J. B. Shear, Proc. Natl. Acad. Sci. U. S. A., 2004, 101, 16104-16108.

82 B. Narupai and A. Nelson, ACS Macro Lett., 2020, 9, 627-638.

83 A. K. Nguyen and R. J. Narayan, Mater. Today, 2017, 20, 314-322.

84 S. Derakhshanfar, R. Mbeleck, K. Xu, X. Zhang, W. Zhong and M. Xing, Bioact. Mater., 2018, 3, 144-156.

85 B. Mu, F. Li and K. S. Walton, Chem. Commun., 2009, 2493-2495.

86 G. W. Ehrenstein and J. Kabelka, in Ullmann's Encyclopedia of Industrial Chemistry, 2000, pp. 453-469.

87 X. Kuang, Z. Zhao, K. Chen, D. Fang, G. Kang and H. J. Qi, Macromol. Rapid Commun., 2018, 39, 1700809.

88 E. Shukrun, I. Cooperstein and S. Magdassi, Adv. Sci., 2018, 5, 1800061.

89 I. Cooperstein, E. Shukrun, O. Press, A. Kamyshny and S. Magdassi, ACS Appl. Mater. Interfaces, 2018, 10, 1887918885.

90 G. Fang, H. Cao, L. Cao and X. Duan, Adv. Mater. Technol., 2018, 3, 1700271.

91 M. Layani, X. Wang and S. Magdassi, Adv. Mater., 2018, 30, 1706344.

92 S. Shukla, X. Vidal, E. P. Furlani, M. T. Swihart, K.-T. Kim, Y.-K. Yoon, A. Urbas and P. N. Prasad, ACS Nano, 2011, 5, 1947-1957.

93 E. Blasco, J. Müller, P. Müller, V. Trouillet, M. Schön, T. Scherer, C. Barner-Kowollik and M. Wegener, $A d v$. Mater., 2016, 28, 3592-3595.

94 Z. B. Sun, X. Z. Dong, W. Q. Chen, S. Nakanishi, X. M. Duan and S. Kawata, Adv. Mater., 2008, 20, 914-919.

95 X. Feng, Z. Yang, S. Chmely, Q. Wang, S. Wang and Y. Xie, Carbohydr. Polym., 2017, 169, 272-281.

96 D. Karalekas, Mater. Des., 2003, 24, 665-670.
97 K. K. Chawla, Composite materials: science and engineering, Springer Science \& Business Media, 2012.

98 P. Parandoush and D. Lin, Compos. Struct., 2017, 182, 3653.

99 J. J. Fallon, S. H. McKnight and M. J. Bortner, Addit. Manuf., 2019, 100810.

100 Y. Li, Z. Feng, L. Huang, K. Essa, E. Bilotti, H. Zhang, T. Peijs and L. Hao, Composites, Part A, 2019, 105483.

101 Y. Sano, R. Matsuzaki, M. Ueda, A. Todoroki and Y. Hirano, Addit. Manuf., 2018, 24, 521-527.

102 Z. Spitalsky, D. Tasis, K. Papagelis and C. Galiotis, Prog. Polym. Sci., 2010, 35, 357-401.

103 N. van de Werken, H. Tekinalp, P. Khanbolouki, S. Ozcan, A. Williams and M. Tehrani, Addit. Manuf., 2020, 31, 100962.

104 S. Singh, S. Ramakrishna and R. Singh, J. Manuf. Process., 2017, 25, 185-200.

105 A. Peterson, I. östergren, A. Lotsari, A. Venkatesh, J. Thunberg, A. Ström, R. Rojas, M. Andersson, L. A. Berglund and A. Boldizar, Biomacromolecules, 2019, 20, 3924-3932.

106 V. C.-F. Li, X. Kuang, A. Mulyadi, C. M. Hamel, Y. Deng and H. J. Qi, Cellulose, 2019, 26, 3973-3985.

107 Q. Q. Wang, Q. Yao, J. Liu, J. Z. Sun, Q. Q. Zhu and H. L. Chen, Cellulose, 2019, 26, 7585-7617.

108 Q. Q. Wang, J. Z. Sun, Q. Yao, C. C. Ji, J. Liu and Q. Q. Zhu, Cellulose, 2018, 25, 4275-4301.

109 N. B. Palaganas, J. D. Mangadlao, A. C. C. de Leon, J. O. Palaganas, K. D. Pangilinan, Y. J. Lee and R. C. Advincula, ACS Appl. Mater. Interfaces, 2017, 9, 34314-34324.

110 N. K. Simha and J. L. Lewis, presented in part at the 2003 Summer Bioengineering Conference, Key Biscayne, FL, USA, 2003.

111 S. Hong, D. Sycks, H. F. Chan, S. Lin, G. P. Lopez, F. Guilak, K. W. Leong and X. Zhao, Adv. Mater., 2015, 27, 4035-4040.

112 J. Wang, A. Chiappone, I. Roppolo, F. Shao, E. Fantino, M. Lorusso, D. Rentsch, K. Dietliker, C. F. Pirri and H. Grützmacher, Angew. Chem., Int. Ed., 2018, 57, 23532356.

113 M. Rothammer, M.-C. Heep, G. von Freymann and C. Zollfrank, Cellulose, 2018, 25, 6031-6039.

114 R. Iley and H. Riley, J. Chem. Soc., 1948, 1362-1366.

115 R. Bacon, J. Appl. Phys., 1960, 31, 283-290.

116 S. Iijima, Nature, 1991, 354, 56-58.

117 D. Young, N. Wetmore and M. Czabaj, Addit. Manuf., 2018, 22, 508-515.

118 B. Brenken, E. Barocio, A. Favaloro, V. Kunc and R. B. Pipes, Addit. Manuf., 2018, 21, 1-16.

119 C. Shemelya, A. De La Rosa, A. R. Torrado, K. Yu, J. Domanowski, P. J. Bonacuse, R. E. Martin, M. Juhasz, F. Hurwitz and R. B. Wicker, Addit. Manuf., 2017, 16, 186196.

120 A. Schmitz, J. Eng. Mater. Technol., 2020, 142, 024501.

121 A. Mitchell, U. Lafont, M. Hołyńska and C. Semprimoschnig, Addit. Manuf., 2018, 24, 606-626. 
122 Y. Liu, W. Xiong, L. J. Jiang, Y. Zhou, D. Li, L. Jiang, J.-F. Silvain and Y. Lu, Laser-directed $3 D$ assembly of carbon nanotubes using two-photon polymerization (Conference Presentation), SPIE, 2017.

123 S. Ghoshal, Fibers, 2017, 5, 40.

124 G. Gonzalez, A. Chiappone, I. Roppolo, E. Fantino, V. Bertana, F. Perrucci, L. Scaltrito, F. Pirri and M. Sangermano, Polymer, 2017, 109, 246-253.

125 Q. Mu, L. Wang, C. K. Dunn, X. Kuang, F. Duan, Z. Zhang, H. J. Qi and T. Wang, Addit. Manuf., 2017, 18, 74-83.

126 S. Ushiba, S. Shoji, P. Kuray, K. Masui, J. Kono and S. Kawata, presented in part at the Advanced Fabrication Technologies for Micro/Nano Optics and Photonics VI, 2013.

127 S. Ushiba, S. Shoji, K. Masui, P. Kuray, J. Kono and S. Kawata, Carbon, 2013, 59, 283-288.

128 W. Xiong, Y. Liu, L. J. Jiang, Y. S. Zhou, D. W. Li, L. Jiang, J.-F. Silvain and Y. F. Lu, Adv. Mater., 2016, 28, 2002-2009.

129 U. Staudinger, G. Zyla, B. Krause, A. Janke, D. Fischer, C. Esen, B. Voit and A. Ostendorf, Microelectron. Eng., 2017, 179, 48-55.

130 J. Greenhall and B. Raeymaekers, Adv. Mater. Technol., 2017, 2, 1700122.

131 S. Schumann, A. Elschner, A. Sautter, W. Lövenich, R. Sauer, J. Sütterlin and N. Kausch-Busies, US20200013559A1, 2019.

132 K. M. Reza, A. Gurung, B. Bahrami, S. Mabrouk, H. Elbohy, R. Pathak, K. Chen, A. H. Chowdhury, M. T. Rahman and S. Letourneau, J. Energy Chem., 2020, 44, 41-50.

133 H. Dong, E. Zheng, Z. Niu, X. Zhang, Y.-Y. Lin, P. Jain and Q. Yu, ACS Appl. Mater. Interfaces, 2020, 12, 17571-17582.

134 Y. Tao, C. Wei, J. Liu, C. Deng, S. Cai and W. Xiong, Nanoscale, 2019, 11, 9176-9184.

135 D. N. Heo, S.-J. Lee, R. Timsina, X. Qiu, N. J. Castro and L. G. Zhang, Mater. Sci. Eng., C, 2019, 99, 582-590.

136 J. Y. Oh, M. Shin, J. B. Lee, J.-H. Ahn, H. K. Baik and U. Jeong, ACS Appl. Mater. Interfaces, 2014, 6, 6954-6961.

137 J. Nevrela, M. Micjan, M. Novota, S. Kovacova, M. Pavuk, P. Juhasz, J. Kovac Jr., J. Jakabovic and M. Weis, J. Polym. Sci., Part B: Polym. Phys., 2015, 53, 1139-1146.

138 F. P. W. Melchels, M. A. N. Domingos, T. J. Klein, J. Malda, P. J. Bartolo and D. W. Hutmacher, Prog. Polym. Sci., 2012, 37, 1079-1104.

139 H. N. Chia and B. M. Wu, J. Biol. Eng., 2015, 9, 4.

140 E. Mancha Sánchez, J. C. Gómez-Blanco, E. López Nieto, J. G. Casado, A. Macías-García, M. A. Díaz Díez, J. P. Carrasco-Amador, D. Torrejón Martín, F. M. SánchezMargallo and J. B. Pagador, Front. Bioeng. Biotechnol., 2020, 8, 776.

141 E. Sanchez-Rexach, T. G. Johnston, C. Jehanno, H. Sardon and A. Nelson, Chem. Mater., 2020, 32, 7105-7119.

142 Z. Zhao, C. Wang, H. Yan and Y. Liu, Adv. Funct. Mater., 2019, 29, 1905911.

143 S. H. Kim, Y. K. Yeon, J. M. Lee, J. R. Chao, Y. J. Lee, Y. B. Seo, M. T. Sultan, O. J. Lee, J. S. Lee, S.-I. Yoon,
I.-S. Hong, G. Khang, S. J. Lee, J. J. Yoo and C. H. Park, Nat. Commun., 2018, 9, 1620.

144 A. Blanazs, S. P. Armes and A. J. Ryan, Macromol. Rapid Commun., 2009, 30, 267-277.

145 S. O. Kim, H. H. Solak, M. P. Stoykovich, N. J. Ferrier, J. J. de Pablo and P. F. Nealey, Nature, 2003, 424, 411-414.

146 G. R. Whittell and I. Manners, Adv. Mater., 2007, 19, 3439-3468.

147 G. R. Whittell, M. D. Hager, U. S. Schubert and I. Manners, Nat. Mater., 2011, 10, 176-188.

148 J.-C. Eloi, L. Chabanne, G. R. Whittell and I. Manners, Mater. Today, 2008, 11, 28-36.

149 C. Y. Huang, in Current Trends of Optics and Photonics, ed. C. C. Lee, 2015, vol. 129, pp. 263-271.

150 H. Finkelmann, M. Happ, M. Portugal and H. Ringsdorf, Makromol. Chem., 1978, 179, 2541-2544.

151 H. Finkelmann, H. Ringsdorf and J. H. Wendorff, Makromol. Chem., 1978, 179, 273-276.

152 D. J. Broer, G. N. Mol and G. Challa, Makromol. Chem., 1991, 192, 59-74.

153 D. J. Broer, R. A. Hikmet and G. Challa, Makromol. Chem., 1989, 190, 3201-3215.

154 D. J. Broer, J. Boven, G. N. Mol and G. Challa, Makromol. Chem., 1989, 190, 2255-2268.

155 D. J. Broer and G. N. Mol, Polym. Eng. Sci., 1991, 31, 625631.

156 J. Schultz, J. Bhatt, R. Chartoff, R. Pogue and J. Ullett, J. Polym. Sci., Part B: Polym. Phys., 1999, 37, 1183-1190.

157 J. Schultz and R. Chartoff, Polymer, 1998, 39, 319-325.

158 J. Schultz, R. Chartoff and J. Ullett, J. Polym. Sci., Part B: Polym. Phys., 1998, 36, 1081-1089.

159 J. Li, C.-H. Wen, S. Gauza, R. Lu and S.-T. Wu, J. Disp. Technol., 2005, 1, 51.

160 J. Li, S.-T. Wu, S. Brugioni, R. Meucci and S. Faetti, J. Appl. Phys., 2005, 97, 073501.

161 T. T. Alkeskjold, J. Lægsgaard, A. Bjarklev, D. S. Hermann, J. Broeng, J. Li, S. Gauza and S.-T. Wu, Appl. Opt., 2006, 45, 2261-2264.

162 H. Chen, R. Zhu, J. Zhu and S.-T. Wu, Liq. Cryst., 2015, 42, 1738-1742.

163 Z. He, Y.-H. Lee, D. Chanda and S.-T. Wu, Opt. Express, 2018, 26, 21184-21193.

164 K. Tanaka, Y. Yahagi, H. Fujisawa, T. Gotou, K. Murai, K. Mitsuhata and K. Nakamura, US10120206, 2018.

165 Y. P. Huang, in Current Trends of Optics and Photonics, ed. C. C. Lee, Springer-Verlag Berlin, Berlin, 2015, vol. 129, pp. 309-319.

166 S. Yang and Y. Liu, Ultrasonics, 2018, 88, 193-206.

167 T. J. White, A. D. Zhao, S. A. Cazzell, T. J. Bunning, T. Kosa, L. Sukhomlinova, T. J. Smith and B. Taheri, J. Mater. Chem., 2012, 22, 5751-5757.

168 M. Giese, J. C. De Witt, K. E. Shopsowitz, A. P. Manning, R. Y. Dong, C. A. Michal, W. Y. Hamad and M. J. MacLachlan, ACS Appl. Mater. Interfaces, 2013, 5, 6854-6859.

169 H. Zeng, P. Wasylczyk, C. Parmeggiani, D. Martella and D. S. Wiersma, J. Visualized Exp., 2016, e53744. 
170 H. Zeng, P. Wasylczyk, G. Cerretti, D. Martella, C. Parmeggiani and D. S. Wiersma, Appl. Phys. Lett., 2015, 106, 111902.

171 M. Fleisch, S. Gao, D. Bošnjaković, X. Zhang, R. Rupp and I. Drevenšek-Olenik, Liq. Cryst., 2019, 46, 2075-2084.

172 E. Sungur, M.-H. Li, G. Taupier, A. Boeglin, M. Romeo, S. Méry, P. Keller and K. D. Dorkenoo, Opt. Express, 2007, 15, 6784-6789.

173 J. S. Ullett, T. Benson-Tolle, J. W. Schultz and R. Chartoff, Mater. Des., 1999, 20, 91-97.

174 C. C. Tartan, P. S. Salter, M. J. Booth, S. M. Morris and S. J. Elston, J. Appl. Phys., 2016, 119, 183106.

175 C. Tartan, P. Salter, T. Wilkinson, M. Booth, S. Morris and S. Elston, $R S C A d v$. , 2017, 7, 507-511.

176 H. Yoshida, G. Nakazawa, K. Tagashira and M. Ozaki, Soft Matter, 2012, 8, 11323-11327.

177 L. Li, Q. Lin, M. Tang, A. J. Duncan and C. Ke, Chem. Eur. J., 2019, 25, 10768-10781.

178 D. Liu and D. J. Broer, Langmuir, 2014, 30, 1349913509.

179 J. Ullett, J. Schultz and R. Chartoff, Rapid Prototyping J., 2000, 6, 8-17.

180 H. Zeng, D. Martella, P. Wasylczyk, G. Cerretti, J. C. G. Lavocat, C. H. Ho, C. Parmeggiani and D. S. Wiersma, Adv. Mater., 2014, 26, 2319-2322.

181 D. Martella, D. Antonioli, S. Nocentini, D. Wiersma, G. Galli, M. Laus and C. Parmeggiani, RSC Adv., 2017, 7, 19940-19947.

182 S. Nocentini, D. Martella, C. Parmeggiani, S. Zanotto and D. S. Wiersma, Adv. Opt. Mater., 2018, 6, 1800167.

183 H. Zeng, P. Wasylczyk, C. Parmeggiani, D. Martella, M. Burresi and D. S. Wiersma, Adv. Mater., 2015, 27, 3883-3887.

184 D. Martella, S. Nocentini, D. Nuzhdin, C. Parmeggiani and D. S. Wiersma, Adv. Mater., 2017, 29, 1704047.

185 S. Nocentini, F. Riboli, M. Burresi, D. Martella, C. Parmeggiani and D. S. Wiersma, ACS Photonics, 2018, 5, 3222-3230.
186 A. Mouquinho, M. Saavedra, A. Maiau, K. Petrova, M. T. Barros, J. Figueirinhas and J. Sotomayor, Mol. Cryst. Liq. Cryst., 2011, 542, 132-140.

187 J. Cooper, Waters Corporation, Application Note $720004814 e n, 2013$.

188 J. J. Sandford O’Neill, P. S. Salter, M. J. Booth, S. J. Elston and S. M. Morris, Nat. Commun., 2020, 11, 2203.

189 C. C. Tartan, J. J. Sandford, O’Neill, P. S. Salter, J. Aplinc, M. J. Booth, M. Ravnik, S. M. Morris and S. J. Elston, Adv. Opt. Mater., 2018, 6, 1800515.

190 B. Akdeniz and E. Bukusoglu, Langmuir, 2019, 35, 1312613134.

191 M. Del Pozo, C. Delaney, C. W. Bastiaansen, D. Diamond, A. P. Schenning and L. Florea, ACS Nano, 2020, 14, 98329839.

192 L. Chen, Y. Dong, C.-Y. Tang, L. Zhong, W.-C. Law, G. C. Tsui, Y. Yang and X. Xie, ACS Appl. Mater. Interfaces, 2019, 11, 19541-19553.

193 E. Descrovi, F. Pirani, V. P. Rajamanickam, S. Licheri and C. Liberale, J. Mater. Chem. C, 2018, 6, 10428-10434.

194 S. Kitagawa, R. Kitaura and S. Noro, Angew. Chem., Int. Ed., 2004, 43, 2334-2375.

195 J. R. Li, R. J. Kuppler and H. C. Zhou, Chem. Soc. Rev., 2009, 38, 1477-1504.

196 J. Lee, O. K. Farha, J. Roberts, K. A. Scheidt, S. T. Nguyen and J. T. Hupp, Chem. Soc. Rev., 2009, 38, 1450-1459.

197 H. Furukawa, K. E. Cordova, M. O’Keeffe and O. M. Yaghi, Science, 2013, 341, 1230444.

198 G. Ferey, Chem. Soc. Rev., 2008, 37, 191-214.

199 O. Halevi, J. M. Tan, P. S. Lee and S. Magdassi, Adv. Sustainable Syst., 2018, 2, 1700150.

200 N. Maldonado, V. G. Vegas, O. Halevi, J. I. Martínez, P. S. Lee, S. Magdassi, M. T. Wharmby, A. E. Platero-Prats, C. Moreno and F. Zamora, Adv. Funct. Mater., 2019, 29, 1808424.

201 O. Halevi, J. Chen, G. Thangavel, S. A. Morris, T. B. Uliel, Y. R. Tischler, P. S. Lee and S. Magdassi, RSC Adv., 2020, 10, 14812-14817. 